José Ramón Alonso Pereira

Figura 1. Pabellón Suizo y Colegio de España, foto de conjunto (archivo CUP).

José Ramón Alonso Pereira.

Arquitecto ETSAM, doctor UPM, catedrático ETSAC Universidad de La Coruña.

\title{
El Pabellón Suizo y el Colegio de España en París
}

\section{Un análisis comparativo}

Palabras clave: arquitectura del siglo XX, tradición y vanguardia, Le Corbusier, Pabellón Suizo, Colegio de España, Cité Universitaire de París.

La Cité Internationale Universitaire de París vio la luz en una Europa que, tras la Guerra de 1914-1918, reformulaba sus modelos universitarios. Sus edificios presentan un amplio registro arquitectónico que pasa de los estilos nacionales a la modernidad, haciendo de la Cité un reflejo de la pluralidad de la arquitectura del siglo XX. El Pabellón Suizo y el Colegio de España reflejan esa pluralidad (Figura 1). Si el Pabellón es emblema de la modernidad y de la arquitectura corbuseriana, el Colegio simboliza los compromisos aún vigentes con la tradición. La coincidencia del programa y el paralelismo del lugar permiten confrontarlos y analizarlos comparativamente. Basado en documentos depositados en la Cité Universitaire, el Pabellón Suizo, el Colegio de España y otros archivos, este trabajo se propone explicar y analizar su arquitectura, oponiendo ambas obras para entenderlas mejor y entender asi un tiempo histórico que se debate en toda Europa entre tradición y vanguardia.

\section{Tiempo histórico e ideales urbanos}

El contexto histórico de la Cité UniversiEtaire de París corresponde a un tiempo de cambios sin precedentes, en que se alteró sustancialmente la estructura de la sociedad y la politica, del comportamiento colectivo y de la organización del trabajo y del ocio. Fueron los años de la segunda revolución industrial: la de la electricidad, el acero, la química, el automóvil y la radio. Los años de la mejora de las condiciones de vida. Los años de la aparición de las masas como protagonistas de la vida colectiva. En arquitectura fueron los años del tránsito de la tradición académica a la vanguardia moderna.

En el campo urbano estos años tuvieron su reflejo en las relaciones que se establecieron en París entre la ciudad central y su periferia o banlieue, dentro de cuyo contexto urbanístico surge la Cité Universitaire de París, más que como una alternativa urbana, como un ejemplo singular de los ideales rurbanos de su tiempo, que aspiraban a fundir la naturaleza y la urbanidad.

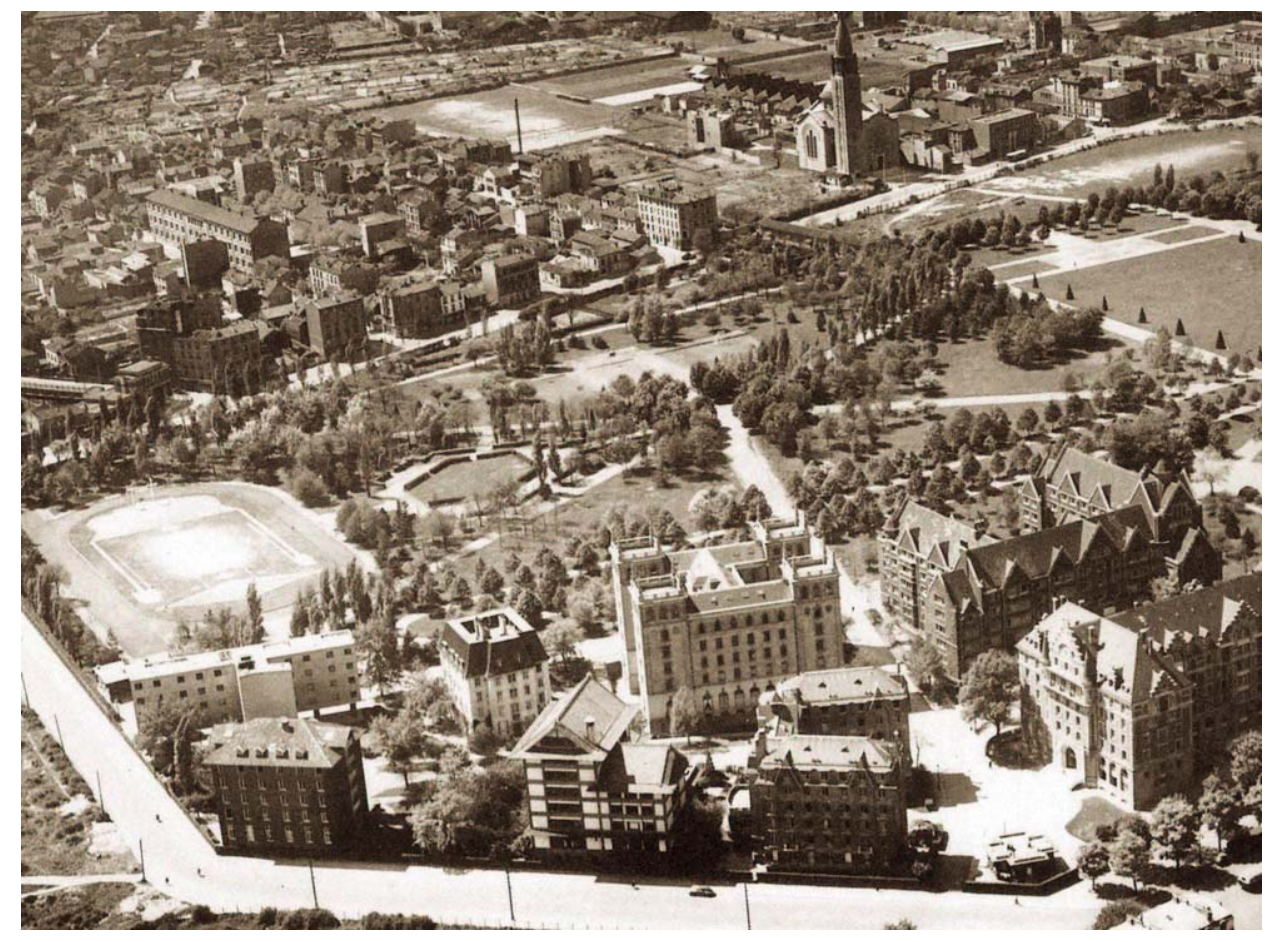




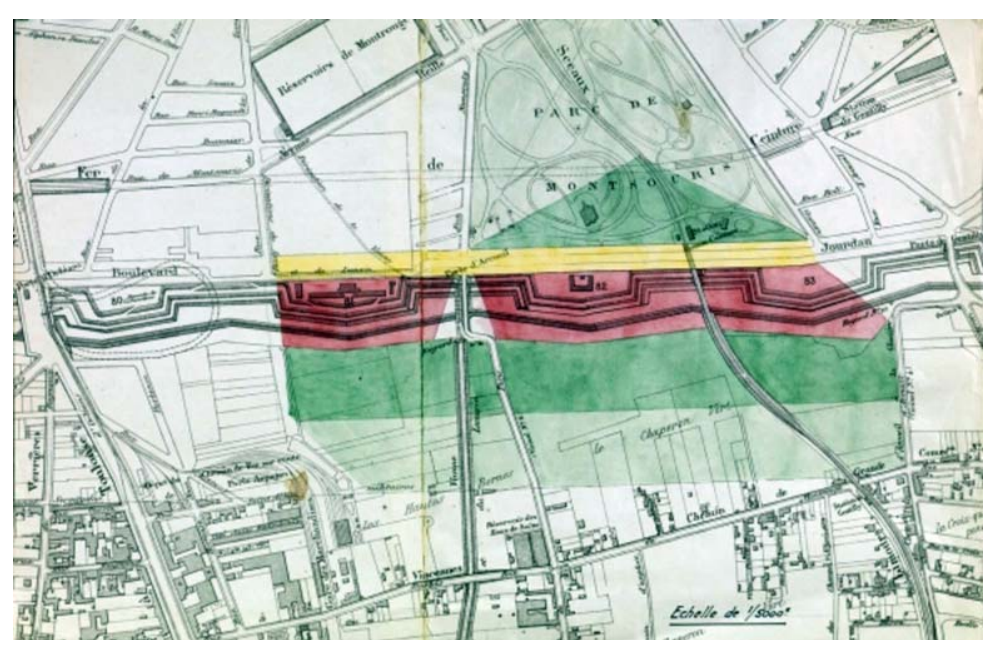

Figura 2. Cité Universitaire: planimetria fortificaciones (archivo CUP).

Heredera de debates y propuestas del siglo XIX, la más conocida de esas alternativas rurbanas es la Garden City o Ciudad Jardin definida desde 1898 por Ebenezer Howard. A su lado destaca la Ciudad Lineal, ideada en 1882 por Arturo Soria. Una y otra ampliaron y extendieron sus conceptos en estos años, llevando el nombre no solo a las garden cities: autónomas e independientes, sino también a las garden villages: colonias dentro de las capitales y a los garden suburbs: barrios periféricos creados para desahogar las ciudades, adulterándose así los planteamientos anteriores de alternativa urbana.

En Francia, el modelo británico --y más tarde el modelo lineal español-- fueron importados y difundidos por Georges Benoit-Lévy (1880-1971), haciéndose propagandista de ellos por toda Europa, aunque asimilando sus ideas a una variante higiénica de las industrial villages.

Por su parte, sin el aparato teórico y propagandístico europeo, los hombres del medio oeste americano buscaron a finales del XIX sintetizar lo rural y lo urbano en un continuo de prairie towns, bosques colectivos puntuados por viviendas: las prairie houses, que --al contrario que en Europa-- no son unas casas con un jardín, sino unas casas en un jardín comunal.

Ambas aportaciones: las de la Garden City y las de los Prairie Towns tuvieron reflejo en los planteamientos y soluciones de la Cité Universitaire de París.

\section{La Cité Universitaire de Paris}

Cuando las capitales europeas se enfrentaron en los años veinte a la creación de nuevos recintos universitarios, buscaron una formulación arquitectónica a través de diferentes modelos urbanísticos.

A comienzos del siglo XX eran tres los principales modelos universitarios vigen- tes en Europa: la universidad británica de colleges que aunaba docencia y convivencia, la universidad francesa de alta docencia, conferidora de títulos habilitantes, y la universidad alemana que primaba la investigación, derivando de ella la docencia. A ellas se les había unido recientemente como modelo propio el de la universidad norte-americana: la llamada 'ciudad universitaria', con dotaciones para el desarrollo integral de la vida académica. Estos nuevos modelos urbanísticos dieron lugar a grandes áreas o ciudades universitarias, si bien con tres modelos diferenciados: la ciudad universitaria docente, la ciudad universitaria residencial, y la ciudad universitaria integral, a la vez docente y vivencial. En contraste con la Ciudad Universitaria de Madrid que, como las americanas, reúne facultades, residencias y servicios, o con la de Roma: facultades sólo, sin ninguna residencia universitaria, la de París presenta sólo residencias, sin centros docentes propios. Interesa resaltar no sólo el momento histórico común de las tres, sino también la coincidencia generacional entre sus promotores y sus proyectistas.

La Cité Universitaire de París vio la luz en el seno de un mundo que, tras la Guerra Europea, deseaba reconstruir el diálogo entre sus pueblos. Fue propuesta por André Honnorat (1868-1950) ministro de Educación, como un lugar dedicado a residencia de estudiantes, donde los jóvenes universitarios -vistos entonces como las élites del futuro- de todos los países aprendieran a conocerse y a vivir juntos. $\mathrm{Su}$ ánimo era convertir Francia en un centro cosmopolita: "reconstruir alrededor de la Universidad de París los collèges de las naciones que le dieron desde la Edad Media su carácter de universalidad y le hicieron ser el primer foyer espiritual del mundo" (Lemoine 1990). Creada en junio de 1921, en los años sucesivos se logró interesar en el proyecto a estadistas de diversos países, organizándose un amplio soporte social y humano. España y Suiza, ambas neutrales durante la Guerra, no quisieron quedar al margen de este proyecto universitario.

Apoyándose en la Ley de 1919 que reemplazó las fortificaciones de París por un anillo verde de $35 \mathrm{~km}$ de largo por casi 400 $\mathrm{m}$ de fondo, autorizando viviendas sociales y equipamientos, el Estado cedió a la Universidad la zona comprendida entre las puertas de Gentilly y Arcueil, junto al Parque Monsouris (figura 2). En junio de 1920 se encomendó el estudio urbanístico a Jean-Luc Forestier (1861-1930) y el proyecto general a Lucien Bechmann (18801968). Éste organizó los alojamientos en 
Figura 4. Cité Universitaire: planimetria Bechmann (archivo CUP).
Figura 4. Cité Universitaire en 1939, vista aérea (archivo CUP).X

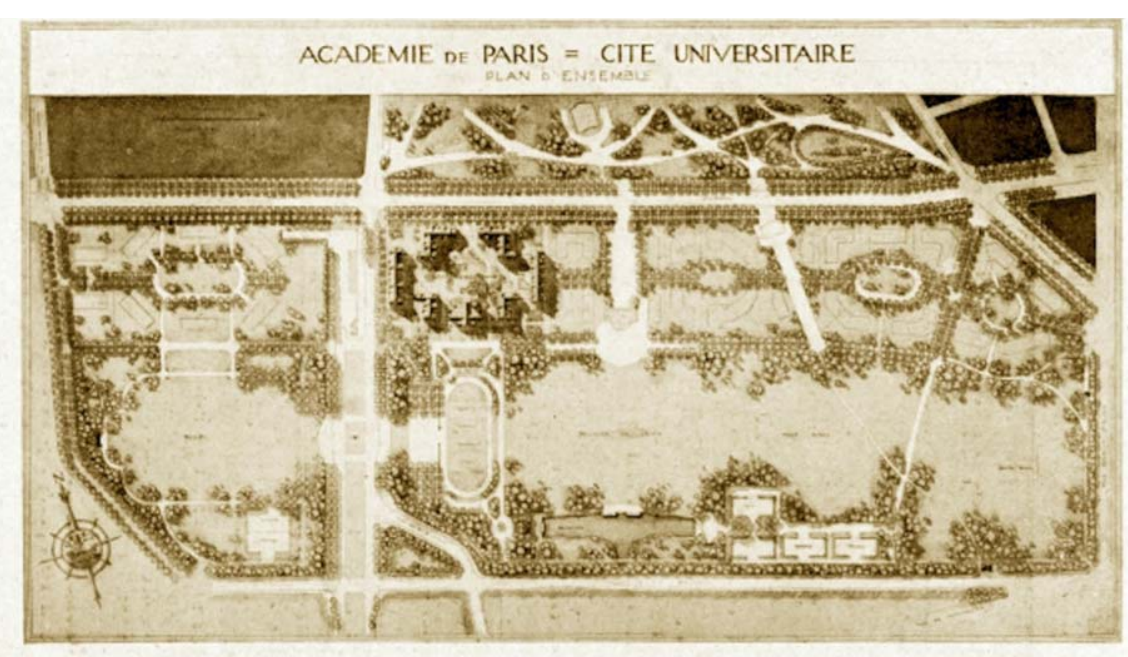

pequeños pabellones o maisons articulados al modo de los campus británicos (Dreyfuss-See 2000; figura 3); aquél proyectó un vasta zona verde con jardines ligados a campos de juego, enlazando así con los ideales de la Garden City y anticipando los de la Ville Radieuse (Cohen, Lortie 1991).

La Universidad de París cedía a las distintas fundaciones nacionales superficies proporcionales al número de estudiantes a alojar, a condición de observar ciertas obligaciones sobre la organización y construcción de los edificios que, una vez equipados, habian de ser donados a la Universidad. Ese compromiso previo se llamaba acta de donación y suponía el arranque del proyecto y las obras.

No se estableció ninguna regla para nombrar o seleccionar a los arquitectos, aunque los franceses construyeron la mayor parte de los pabellones, solos o colaborando con profesionales locales. En los proyectos se dejó libertad formal a cada país, aunque recomendando evocar la especificidad nacional con significantes identificables. La mayoría optó por fórmulas historicistas o regionalistas, si bien algunos prefirieron reflejar el estilo de la época más que el del país, como Dudok y Le Corbusier, que quisieron expresar el espiritu moderno en el Colegio Holandés (1927-38) y en el Pabellón Suizo (1930-32). Así, la Cité Universitaire de París refleja la pluralidad de la arquitectura de su tiempo (Lemoine 1990).

Entre 1925 y 1939 se construyeron 22 edificios (archivo CUP). Promovió el primero la Fundación Deutsch de la Meurthe en 1921, con proyecto de Bechmann; le siguieron en 1924 la belga, la canadiense y la argentina; en 1927, la Casa de Japón, la de Indochina, la de Holanda, la de Suecia, la de Estados Unidos, el Colegio de España y el Franco-británico; en 1928, la Fundación armenia; en 1929, la danesa, la cubana y la de Mónaco; en 1930, la Fundación Helénica y la de las Provincias de Francia; en 1931, la Fundación Suiza.

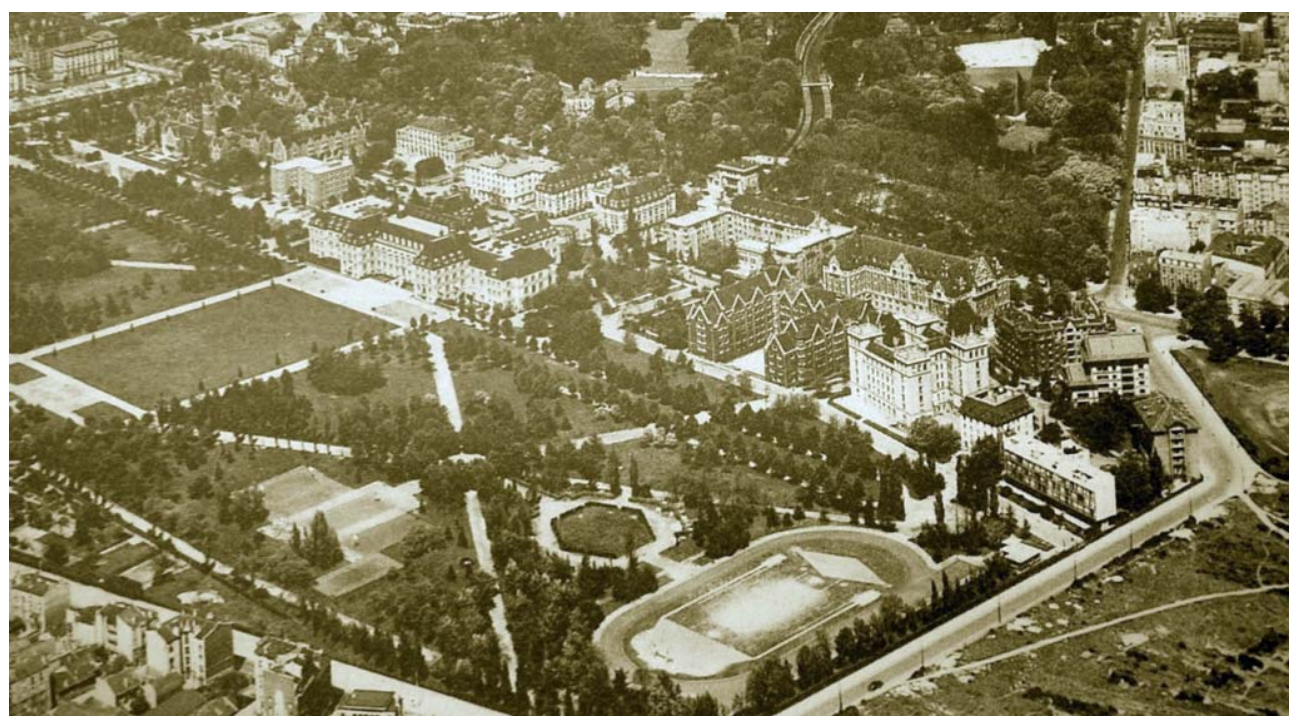


Figura 5. Colegio de España, publicación e imagen de conjunto (L'Architecture, 1938).

Figura 6. Colegio de España, imagen de conjunto (archivo $A C E)$.
Cada edificio disponía de salas de reunión, comedores, y baños colectivos. El conjunto de la Cité se dotó de teatro, salas de deportes, piscina, restaurante e incluso servicio médico y oficina de correos. En vísperas de la Guerra Mundial la Cité contaba con 2.400 residentes (figura 4).

\section{La Cité Universitaire: de Garden City a Ville Radieuse}

Como se ha indicado, en el campo urbanístico la Cité Universitaire surge enmarcada en la dialéctica que se estableció entre la ciudad central y su área metropolitana. Esta relación entre el centro y la periferia tuvo su mejor expresión en París en la urbanización del cinturón periférico surgido tras destruir las fortificaciones, donde se aunaron parques, equipamientos públicos y viviendas sociales (Cohen-Lortie 1991). Ahí se asentó la Cité Universitaire. La operación quiso abordarse con conceptos propios de ciudad jardin, con las variantes que este concepto tenía para los urbanistas franceses de su tiempo, bastante alejados de los planteamientos originales.

El propio Le Corbusier, autor del Pabellón Suizo, mantuvo en estos tiempos una relación ambigua con la ciudad jardin. Si en 1917 tomó contacto con Benoit-Lévy para publicitar sus proyectos, años después sus reflexiones teóricas y la degeneración de

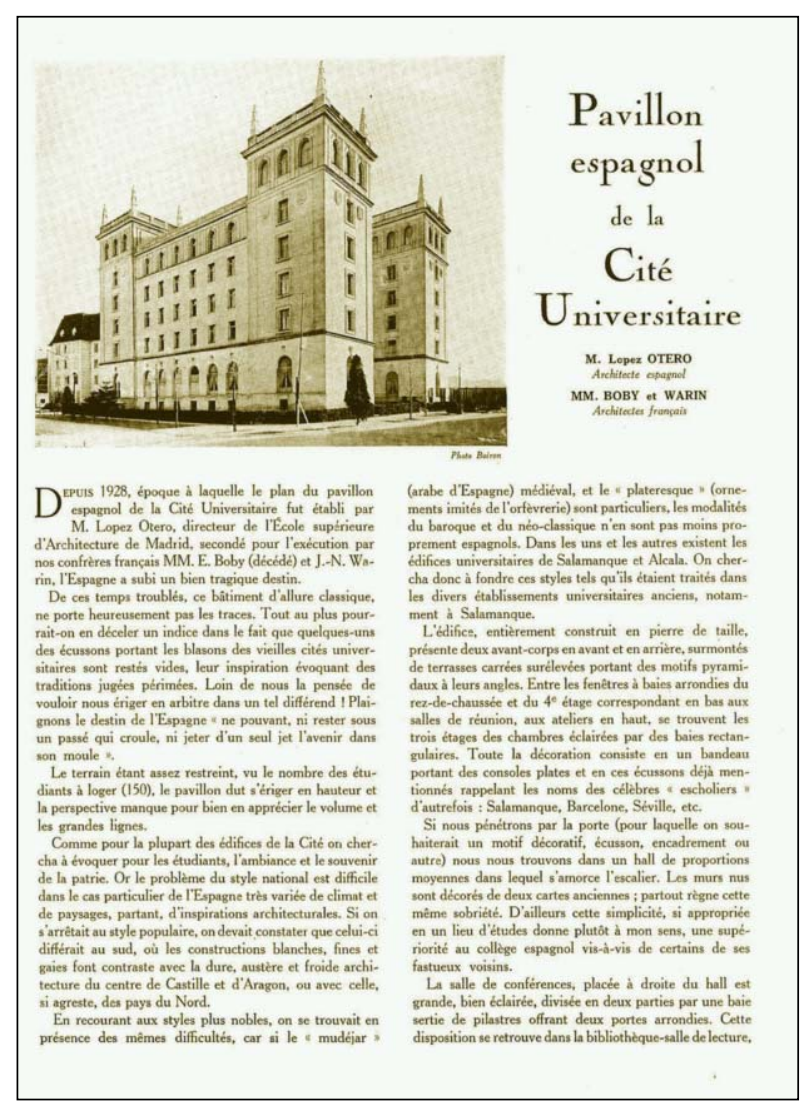

los ideales rurbanos, le llevaron a denostar la ciudad jardin, a la que opuso una ciudad nueva: la Ville Radieuse, imaginada dentro de un parque, como una urbs in ortu a escala metropolitana. Así describe líricamente la ciudad ideal: "Estamos bajo los árboles. El césped nos rodea con inmensas superficies verdes. Aire sano. Ningún ruido. Las casas ya no se ven. A través de las ramas de los árboles se percibe el cielo" (Le Corbusier, 1925). Aunque la descripción pertenece a su Ville Contemporaine ideal, parece una descripción de la Cité Universitaire de París.

También en Madrid, la Ciudad Universitarias se ideó y se proyectó dentro de los ideales de ciudad jardin. Así lo llegó a afirmar López Otero, autor del Colegio de España en París y de la Universitaria madrileña, a la que llamaria expresamente "una universidad jardin" (Chías 1986, Campos 2004). Coetáneos y vecinos en la Cité Universitaire, el Pabellón Suizo y el Colegio de España permiten alcanzar no ya los ideales de la Ciudad Jardin, sino el nuevo ideal corbuseriano de Ville Radieuse.

\section{El Colegio de España}

El Colegio de España pertenece a la vez, podría decirse, a la Cité Universitaire y a la Ciudad Universitaria de Madrid en sus ideales y su arquitectura (Alonso 2013). La idea de su creación surgió en 1924 y se encarriló en junio de $1927,{ }^{1}$ coincidiendo con el 25 aniversario del reinado de Alfonso XIII. Dos meses antes se había creado la Universitaria madrileña, cuyo paralelismo y contemporaneidad son significativos (figuras 5, 6, 7, 8).

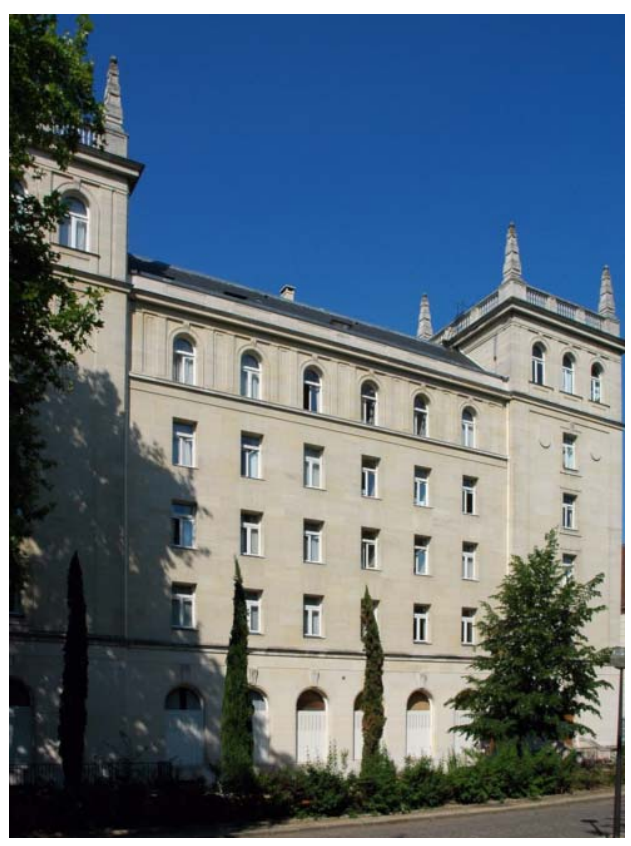


Figura 7. Plantas de parcelas. Izquierda Colegio de España, derecha, Pabellón Suizo (archivos ACE, AFS).

Figura 8. Colegio de España, planimetria (L'Architecture, 1938).

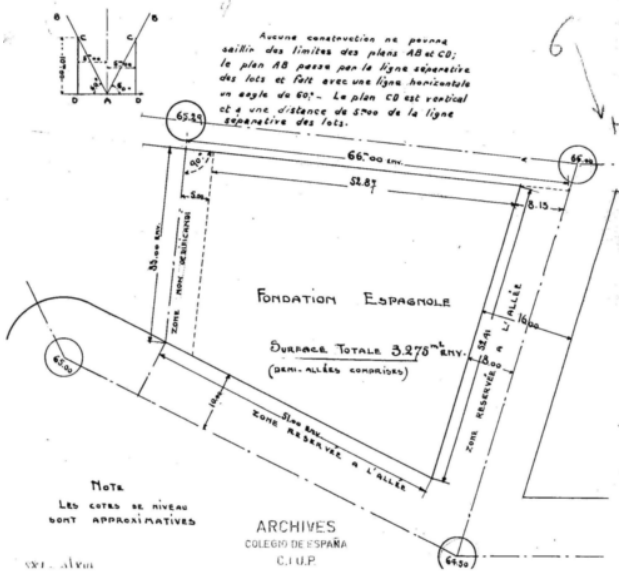

En noviembre se firmó el acta de donación, fijándose en dos años el plazo las de obras. Poco después, en abril de 1928, se encargó a Modesto López Otero (1888- 1962),

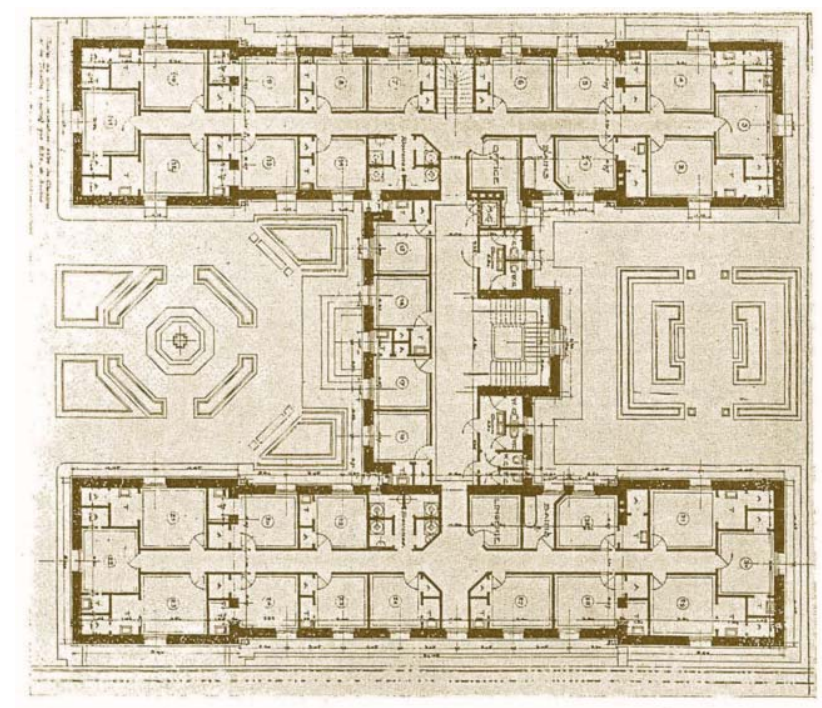

Plan des t́tagrs

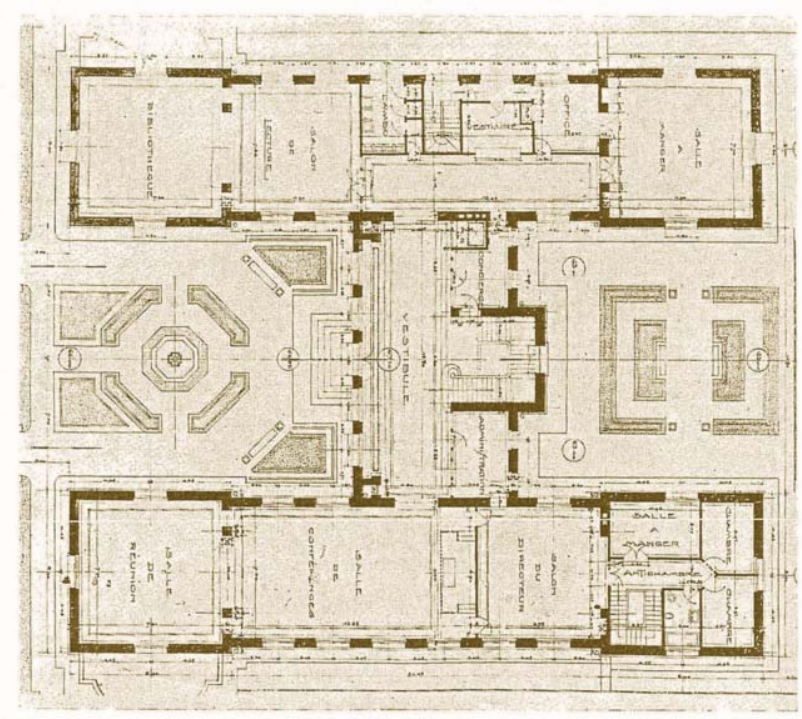

Plan dU REZ-DE-Chaussér

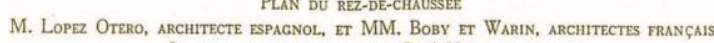
LE paVilLon espagnol a La Cité Universitaire

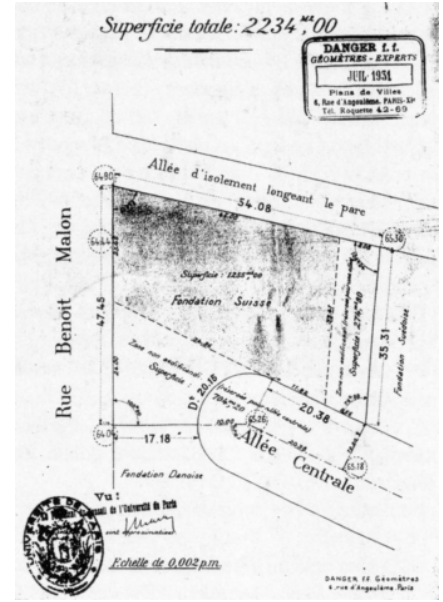

director de la Escuela de Arquitectura de Madrid, la ejecución del proyecto. ${ }^{2}$ Casi al tiempo, la Junta de la Universitaria, presidida por el Rey, nombraba arquitecto de ella a López Otero. Catedrático de proyectos y considerado como el más brillante de su generación, López Otero defendía el orden académico y la composición arquitectónica, sin embargo, tuvo el buen acuerdo de incorporar a la empresa los mejores talentos de entre sus alumnos: Miguel de los Santos, Agustín Aguirre, Manuel Sánchez Arcas, Luis Lacasa, así como a Eduardo Torroja en el ámbito de la ingeniería, haciendo así de la Ciudad Universitaria un laboratorio de la nueva arquitectura. Son todos ellos miembros de la Generación de 1925, cuya labor fue la base del racionalismo español. De este modo, a la retórica organización general rígida y académica del conjunto, se unió la sencillez volumétrica y la simplicidad racional de los edificios, cuyo compromiso entre academia y vanguardia adquirió valor emblemático en la arquitectura española de su tiempo (Flores 1961, Bohigas 1970).

Para el proyecto del Colegio de España, López Otero contó asimismo con la colaboración de Agustín Aguirre, Miguel de los Santos y Eduardo Torroja, sin olvidar la influencia que sobre él tuvieron la racionalidad organizativa y proyectual de Rafael Bergamin y Luis Blanco Soler en las residencias de la Universitaria, imprescindible para explicar el sustrato proyectual del Colegio.

La creación del Colegio y la forma que tomó su instalación - más allá de la función educativa inmediata- se pueden interpretar como una gran operación de política cultural, entendida como una política de promoción de la imagen nacional. Desde el primer momento se puso de manifiesto el deseo consciente de proyec- 


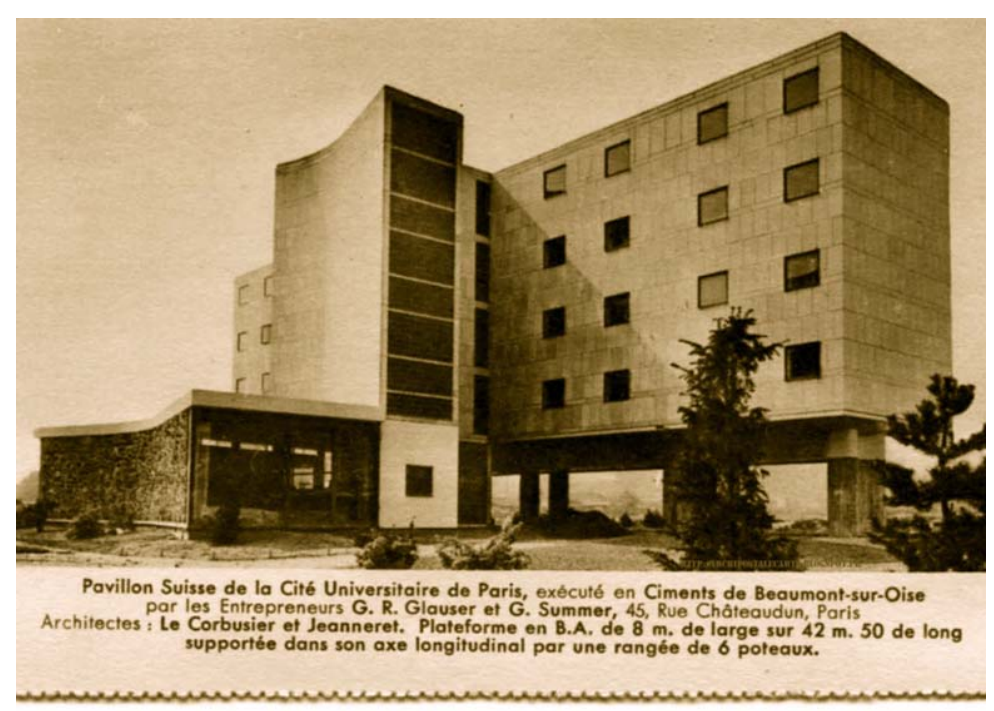

Figura 9. Pabellón Suizo, imagen de conjunto (archivo AFS).

Figura 10. Pabellón Suizo, imagen de conjunto (Oeuvre, 1934). tar una imagen de sí digna de ser exportada (Sazatornil 1997, Niño 2004).

López Otero concibió el Colegio como un edificio exento: un cubo platónico revestido de piedra, que constaba de una planta sótano y cinco sobre rasante. Su claridad volumétrica se reforzaba mediante cuatro torres angulares, emblema de la institución. Realizado el anteproyecto en paralelo con los trabajos iniciales de la Ciudad Universitaria, el 30 de junio de 1928 se remitieron a París los planos, que causaron una grata impresión en la Cité Universitaire por "el depurado arte y el estilo español de suma elegancia con que está concebido" (Doreste 1931).

En otoño de ese año se redactó el proyecto definitivo, que se desarrolló para su ejecución material en los medios franceses y, adaptado a ellos, se sometió a subasta, dando comienzo las obras en septiembre de 1929. La dirección técnica de ellas fue desempeñada por los arquitectos franceses Eugène Boby (1864-1936) y Jean Warin (1901-1970), bajo la inspección y alta dirección de López Otero. ${ }^{3}$

La proclamación de la República en abril de 1931 abrió una etapa de incertidumbre, que tardó un poco en reconducirse $\mathrm{y}$ reconducir a su vez el proceso de construcción, que sufrió una importante demora. En 1932 parecia que iban a darse por finalizadas las obras e inaugurar el Colegio. Las cosas, sin embargo, se retrasaron de nuevo. Aunque desde otoño de 1933 llegaron estudiantes al Colegio, la inauguración oficial se demoró hasta el 10 de abril de 1935 (archivo MAE: R.103.53 y R.647.83).

\section{El Pabellón Suizo}

Vecino del Colegio de España y situado como él en el borde meridional de la Cité Universitaire, el Pabellón Suizo es una obra clave, un seminal building del Movimiento Moderno (archivo FLC, Chantiers 1933, La Construction Moderne 1933), que fue concebido en 1930-1931 y construido en 1932-1933 por Le Corbusier (1887-1965) (figuras 9, 10, 11).

$\mathrm{Su}$ origen se remonta a 1925, cuando varios entes universitarios suizos formularon las bases para fundar en la Cité Universitaire un pabellón para 50 estudiantes. Sin embargo, la lenta recogida de fondos retrasó la decisión hasta la primavera de 1930, mientras el Colegio de España veía ya avanzadas sus obras. Entre 1927 y 1930 se planteó la selección del lugar. La Cité Universitaire ofrecía una parcela-tipo de unos $2100 \mathrm{~m} 2$ para el alojamiento de 100 estudiantes y sólo excepcionalmente admitía subdivisiones. La ampliación del

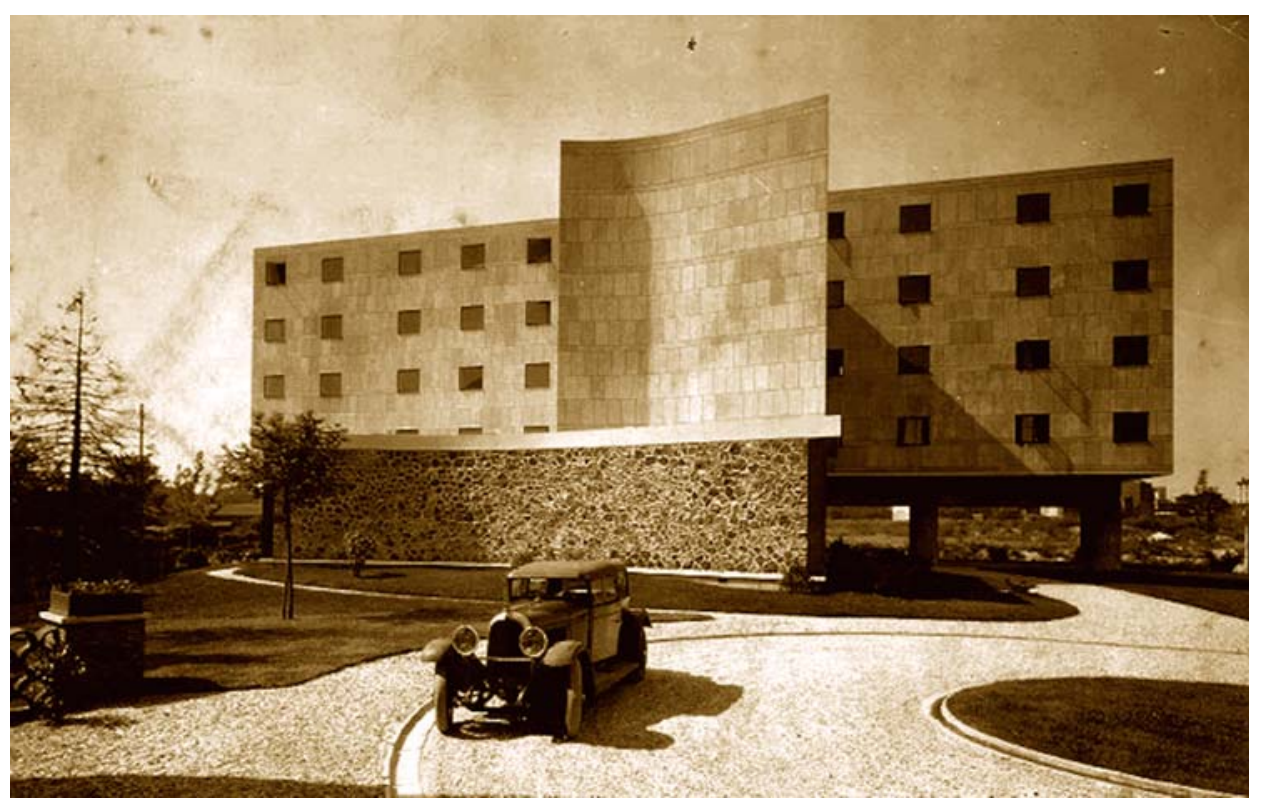


lote de España al decidir el Rey y el Gobierno pasar de 100 a 150 residentes, permitió a Suecia ir a una parcela para sólo 50 estudiantes, y con este precedente pudo plantearse una posible parcela dual para dos países pequeños: Suiza y Dinamarca, que subdividiria entre ambas una parcelatipo (Caillot-Colas 1994).

Tras una intención inicial de convocar un concurso abierto de proyectos, en mayo de 1930 se realizó el encargo oficioso a Le Corbusier, considerado como el principal arquitecto suizo en París, merced al apoyo de Karl Moser, Sigfried Giedion y Raoul La Roche, así como de Rudolf Fueter, presidente del consejo de Universidades suizas y promotor-fundador del Pabellón. E1 encargo se confirmó el 28 de junio, fijándose el programa y dando comienzo a la redacción del proyecto en los meses siguientes (Zaknic 2004). Paradójicamente, este periodo de exaltación suiza coincide con el proceso de nacionalización francesa de Le Corbusier, que culminó en otoño de 1930.

El proceso de proyecto se desarrolló con varias aproximaciones sucesivas: un primer anteproyecto el 14 de enero de 1931, un segundo en febrero, y un tercero en mayo, casi definitivo. Firmada el acta de donación el 10 de julio de 1931, pocas semanas después se entregó el proyecto final, cuyos detalles y especificaciones técnicas se redactarian en los meses sucesivos, teniendo lugar el 14 de noviembre el acto oficial de colocación de la primera piedra, con los sondeos de cimentación en curso. Las obras se desarrollaron con celeridad y sin interrupciones, verificándose la inauguración oficial del Pabellón Suizo el 7 de julio de 1933, en tanto la del Colegio de España se pospondría hasta 1935, si bien ambos recibieron estudiantes por las mismas fechas.

El Pabellón Suizo es un excelente ejemplo de la arquitectura corbuseriana. Es tanto una pieza de ciudad en cuanto manifestación construida de sus ideales urbanos, como un ejemplo paradigmático de la metodología compositiva moderna en su afán de integrar células, servicios y dotaciones. Un bloque esbelto sobre unos musculosos pilotis en su expresión formal, su proyecto es casi como un diagrama que diferencia los elementos singulares y los elementos repetitivos. Éstos forman un prisma elevado del suelo que agrupa las células de las habitaciones por el elemento
Figura 11. Pabellón Suizo, planimetría (Oeuvre, 1934).

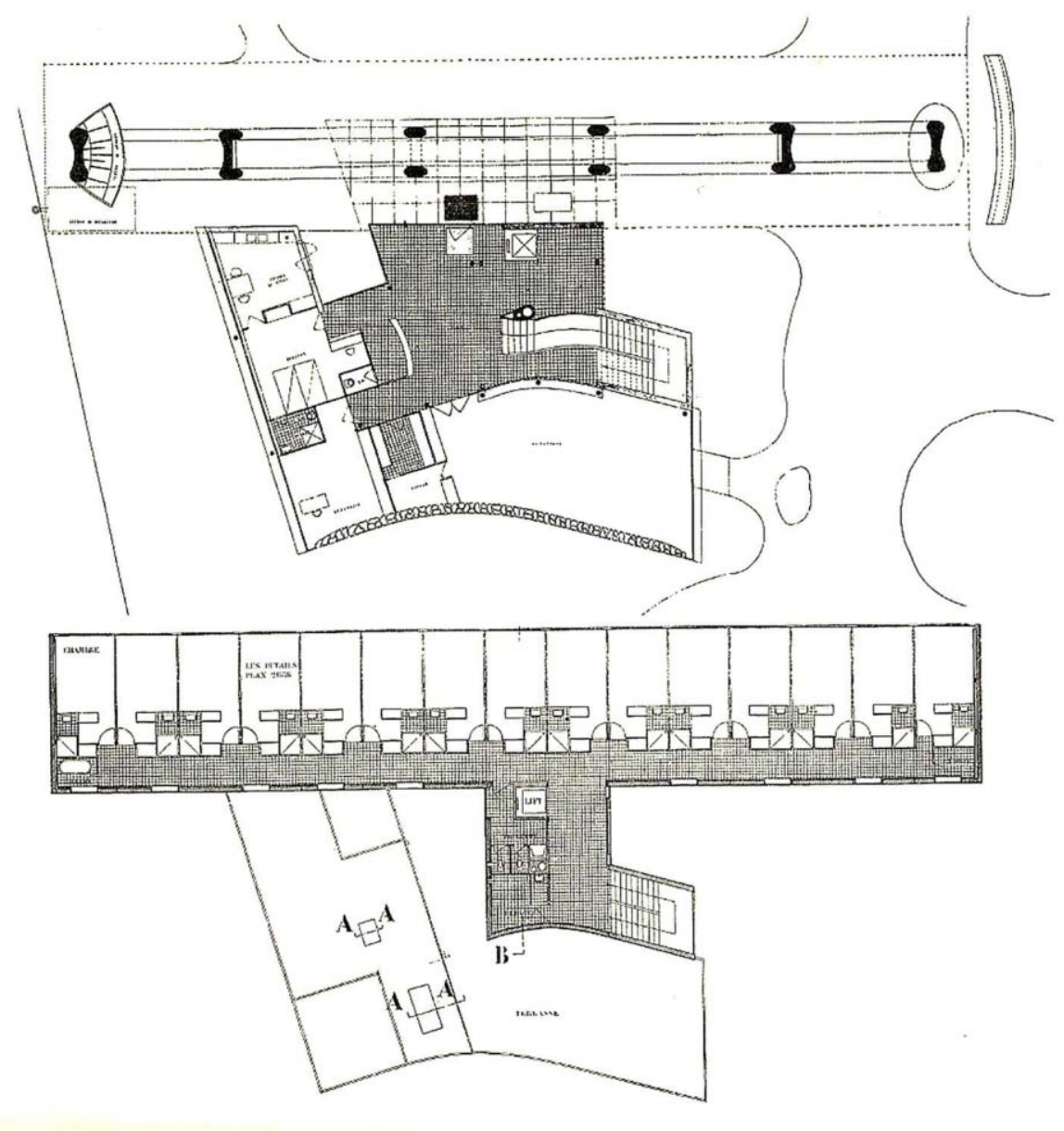


Figura 12.

Pabellón Suizo, imagen conjunto, perspectiva de F. Sammer (Oeuvre, 1934).

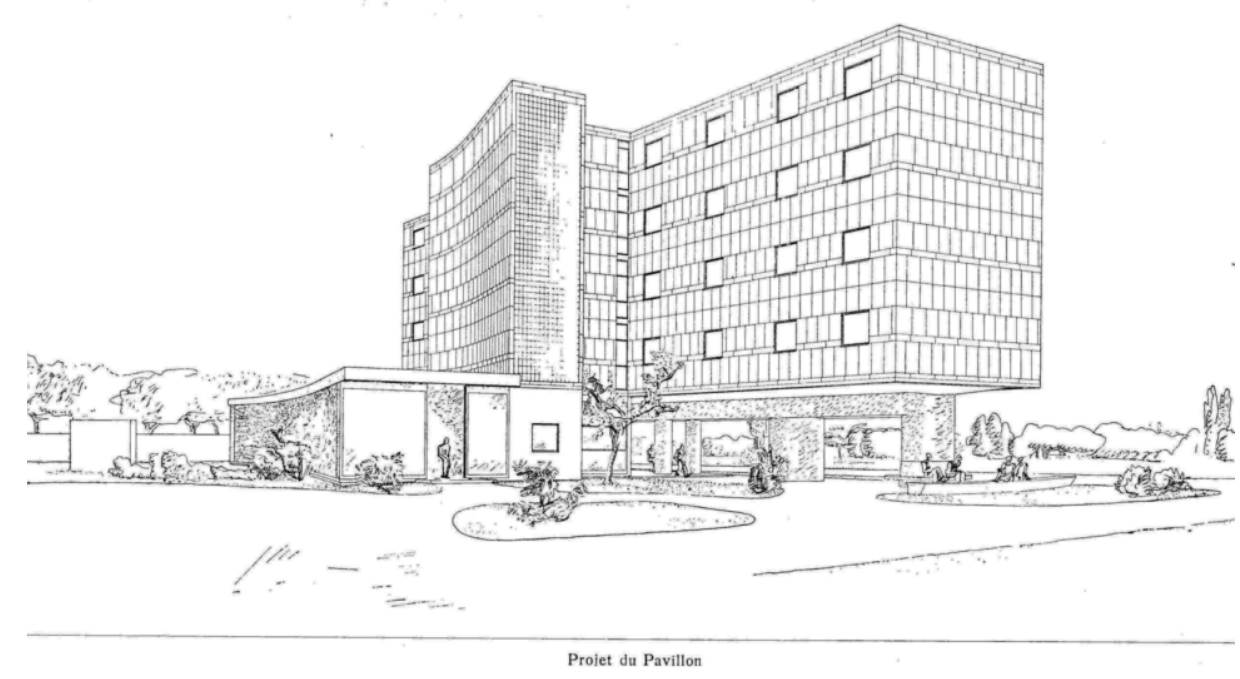

de comunicación más sencillo --una espina recta-- y con la conexión vertical separada para evitar toda idea de confusión. Por su parte, el elemento singular o sala común se separa en otro bloque, anclado al terreno, y se expresa con materiales y texturas distintas (Alonso 2015), al tiempo que establece una ambigua relación dentro-fuera, especialmente rica en la zona de acceso.

En cuanto a la configuración volumétrica y formal, Le Corbusier desarrolla todo un juego de contrarios que conforman una unidad indisoluble. En esta contraposición volumétrica y conceptual están reunidos otros pares de contrarios que refuerzan la tensión entre las dos piezas del edificio: la vida individual y la vida social, el edificio función y el edificio-pasión, la casa de cristal y la casa de piedra, la recta y la curva, los mínimos funcionales y los elementos de composlclón (Agrasar 1990).

\section{Pabellón versus Colegio}

El Pabellón Suizo y el Colegio de España comparten una ubicación singular dentro del conjunto de la Cite Universitaria. En efecto, ambos se sitúan en el sector oriental del conjunto de la Cité: en una especie de anexo trapezoidal al conjunto regular general, cuya superficie se organizaba a su vez en varias parcelas trapezoidales.

Ello planteaba el problema de la ocupación y de la orientación de los edificios en sus solares. Si la Casa de Suecia prefirió mantener la orientación ortogonal del conjunto de las demás residencias de la Cité Universitaire, los otros edificios tomaron opciones particulares más o menos vinculadas a la nueva situación urbana. Así, mientras la Casa del Japón y la de Dinamarca optaron por apoyarse en el viario central del trapecio, López Otero prefirió centrar la entrada del Colegio de España en la vía principal de acceso al parque, trazando un eje que cortaba diagonalmente la parcela y organizando los cuerpos del edificio con independencia de los limites norte y sur. Esta colocación permitía resaltar la visión de las torres desde el acceso y desde la ciudad, haciéndolas el emblema del Colegio. En el Pabellón Suizo, por último, Le Corbusier se sirvió de la forma trapezoidal de la parcela para ocuparla colocando el cuerpo recto en el limite sur, frente al parque de deportes de la Cité, ajustando con habilidad las formas singulares del cuerpo inferior a la irregularidad del limite norte, que queda enmascarado en la respuesta arquitectónica corbuseriana, como evidencia la célebre perspectiva dibujada por Frantisek Sammer (1907-1973), por entonces joven ayudante de Le Corbusier (archivo FLC 1931, Oeuvre 1934; figura 12).

Si éste hacía de la metodología del Movimiento Moderno la base proyectual del Pabellón Suizo, López Otero se apoyaba en el carácter, la tipología y la composición académica como bases del Colegio de España.

López Otero proyectó el Colegio como un edificio exento con cinco plantas sobre rasante, coronadas por cuatro torres angulares. Desechada la distribución con patios de otros proyectos coetáneos, en su tipología organizativa consideró tres esquemas posibles de distribución del edificio: en ' $\mathrm{C}$ ', en ' $\mathrm{E}$ ' y en ' $\mathrm{H}$ ', decidiéndose por este último para dar una mejor solución funcional a los problemas de recorridos e independencia de las zonas habitacionales. Esta planta permitía acceder en el eje de simetría, independizando los espacios a ambos lados y disminuyendo las circulaciones. En esa 'H' las alas alber- 


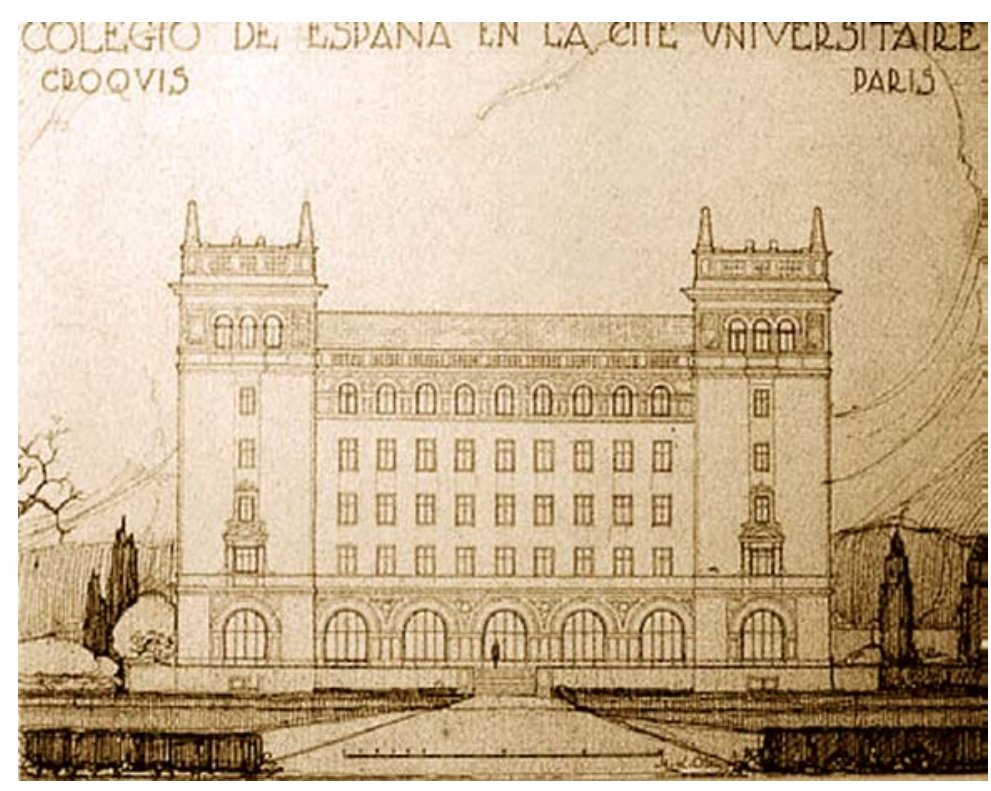

Figura 13. Colegio de España, alzado-perspectivado de A. Aguirre (archivo ACE).

Figura 14. Colegio de España, esquemas compositivos de M. L. Otero (archivo ACE). gan la residencia y las distintas dependencias, mientras en el eje transversal se sitúan las circulaciones verticales y las estancias comunes de cada planta. La similitud de la composición en planta se refuerza en los alzados, revestidos de piedra, que quiso actuar como un material de perennidad que reforzaba la claridad volumétrica y arquitectónica, Sus formas ofrecen un conjunto unitario, conformando una imagen sobria y rotunda, dando tono severo al edificio y austeridad a su decoración. Así, el Colegio de España ejemplifica los compromisos entre tradición y vanguardia en la arquitectura española del momento, como evidencian las perspectivas acuareladas dibujadas por Agustín Aguirre (1896-1985; figura 13), que pueden cotraponerse a las del Pabellón dibujadas por Sammer.

Por su parte, Le Corbusier era ya en esos años un reconocido representante de la modernidad internacional, que acababa de verse constituida en grupo en junio de 1928 en el castillo de La Sarraz en Suiza, donde se crearon los CIAM o Congresos Internacionales de Arquitectura Moderna, de cuya metodología proyectual sería paradigma el Pabellón Suizo. En efecto, el Pabellón es un excelente ejemplo de la obra de Le Corbusier, que en 1925 había formulado sus célebres cinco puntos que se convirtieron en sintagma de la modernidad y que se ejemplificaron en el Pabellón Suizo: el plano y la fachada libre en las plantas repetitivas; la elevación de éstas sobre pilotes que separan el edificio del terreno y enfocan la entrada; la terraza con elementos y carácter diferenciado; la fachada libre, no supeditada a la estructura; y el plano de fenestración que resalta respecto al de fábrica evidenciando la no continuidad entre ambos, haciendo todo ello del Pabellón Suizo la manifestación construida de los ideales corbuserianos (Alonso 2015).

Esas bases o permanencias se evidencian en el proceso de siete meses que media entre el primer anteproyecto y el proyecto definitivo: la idea de la caja de cristal o maison de verre, la del edificio sobre pilotis, las células como base del proyecto, la cubierta singular, y los servicios comunes en un pabellón propio anclado al terreno. Las variaciones sobre estas bases iniciales son en general menores, pero muy significativas (archivo FLC). El muro vitreo, que inicialmente se concebía a base de losetas securit con ventanas centrales en cada habitación, pasa a ser muro continuo transparente, con vidrio armado en su parte baja. Los pilotis, que inicialmente habian sido ligeros y metálicos, pasan a ser de hormigón armado, cada vez más musculosos, para soportar una gran losa o viga armada sobre la que carga una estructura ligera de perfiles de acero que construye las plantas de dormitorios. En cuanto a los servicios comunes, si en enero se planeaba un cuerpo cúbico de igual altura al de dormitorios, en febrero se pasó a un cuerpo de menor altura y formas curvilineas, que concretaria poco a poco su forma y su expresión plástica en las versiones sucesivas, en las que la habilidad proyectual corbuseriana logró una notable calidad arquitectónica.

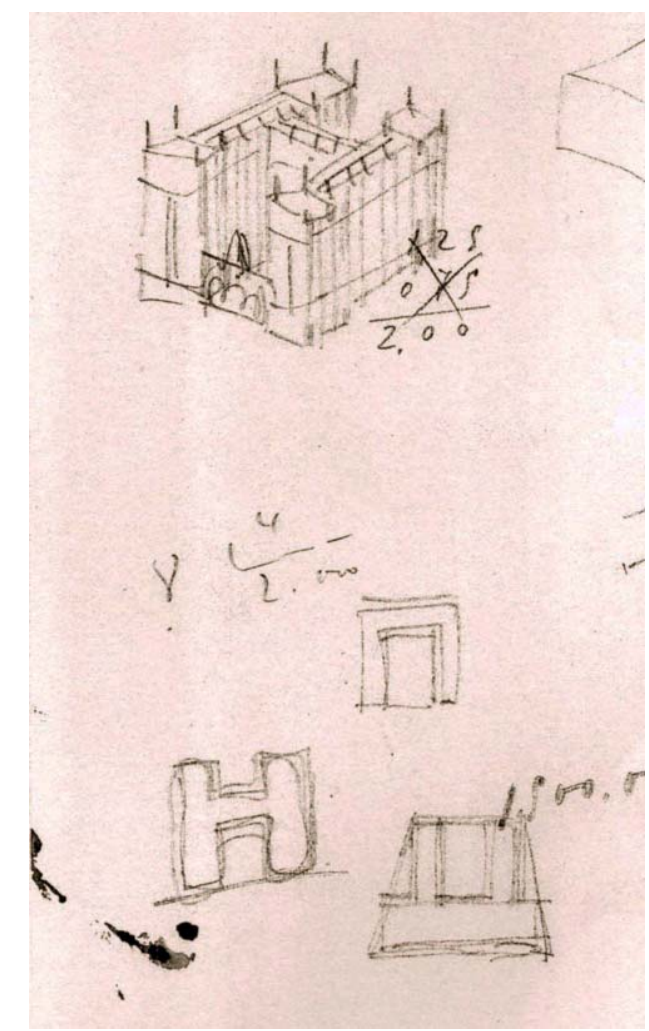


Figura 15. Colegio de España, torre angular, expresión y lenguaje (foto autor).
Si el Colegio es emblema de la arquitectura española de su tiempo, el Pabellón Suizo es paradigma de la modernidad internacional. El análisis comparativo entre uno y otro muestra relaciones evidentes, tanto en los aspectos de organización y composición, como en los procesos constructivos.

\section{Los problemas compositivos}

Aunque los colleges históricos de Oxford y Salamanca o los del antiguo París mencionados por André Honnorat pueden ser referentes lejanos del Pabellón y del Colegio, sus referentes próximos son las obras coetáneas de la Cité Universitaire.

En particular destaca como referencia común de ambos la Fundación Deutsch de la Meurthe (1921-25), primera de todas en la Cité y prototipo de las decisiones ulteriores. Proyectada por Lucien Bechmann, se organiza en seis edificios residenciales en torno a un jardín central, con un pabellón de servicios comunes e identificación formal. Su estilo evoca la arquitectura de los colegios ingleses y sus células de habitación son la base tipológica y dimensional de las residencias posteriores (Dreyfus-See 2000).

Otros referentes --más del Colegio que del Pabellón-- son las grandes fundaciones nacionales vecinas: la belga, la británica y la norteamericana, que contrastan en su tipología organizativa y en sus formas. La organización planimétrica británica es una $\mathrm{U}$ abierta al parque, mientras las otras dos se alinean con el viario exterior, si bien con

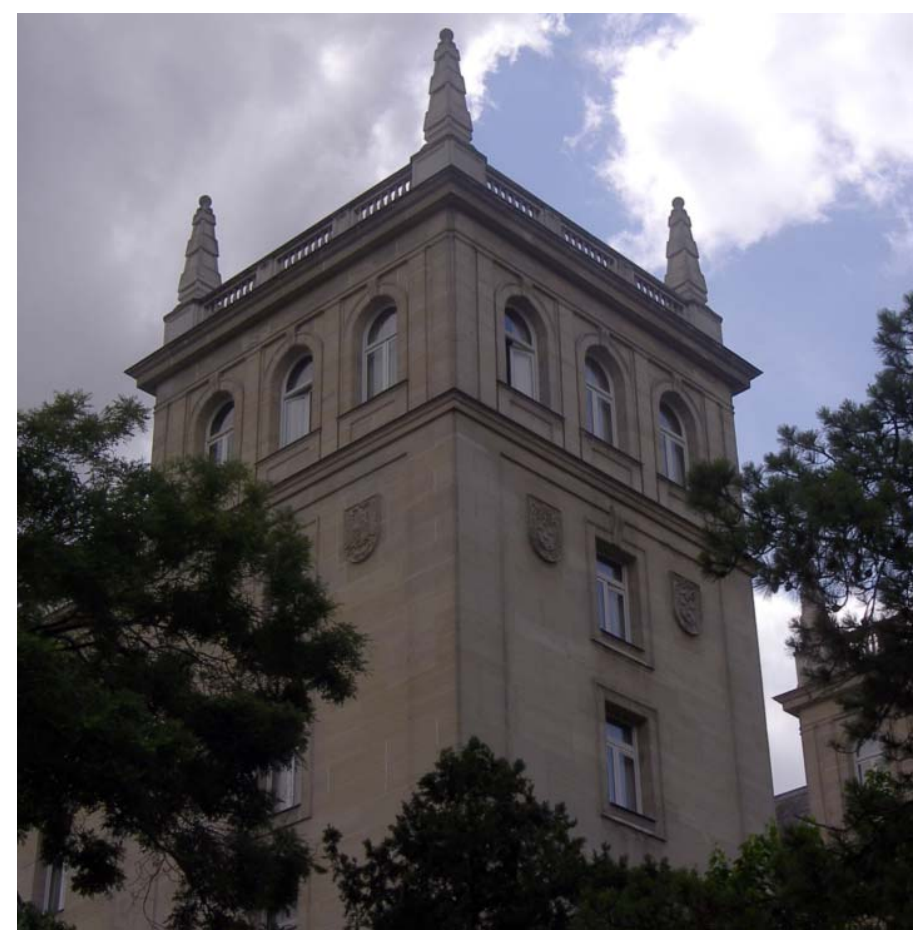

acceso central la estadounidense y con acceso frontal por su lado menor la belga. Sus expresiones formales también difieren. Mientras la franco-británica quiere evocar los centros docentes ingleses, fragmentando su apariencia volumétrica y formal, la belga busca una expresión monumental unitaria mezclando caracteres flamencos y valones, y la norteamericana plantea el habitual modo composicionalista de los grandes edificios universitarios americanos del momento.

Las tres-como todas las demás en la Cité-plantean un problema común: el del carácter o estilo formal. Sobre si inspirarse en la arquitectura áulica o vernácula, religiosa o laica, antigua o reciente, cada uno presenta una respuesta diferente. Los tejados volados, la madera y el empanelado identifican la Casa de Japón, la columnata jónica a la Fundación Helénica, etc. No se escapa de esta intencionalidad la Maison Internationale, proyectada por Bechmann, cuya imagen quiso evocar la arquitectura de Fontainebleau (Lemoine 1990).

El Colegio de España responde a esa voluntad formal en sus bases estilisticas o significativas (figuras 14, 15). Era deseo de sus promotores en Francia y en España que el edificio fuera eminentemente español, es decir, que su arquitectura reflejara la historia nacional. López Otero quiso evocar la gran tradición universitaria humanista de Alcalá o de Salamanca con un diseño 'nacional', abstrayendo los modelos (Sazatornil 1997). Su personalidad reside en sus torres, versión moderna de las del palacio Monterrey. "El Colegio de España -se dijo-- se refiere en su concepción a la tradición universitaria de los siglos XVI y XVII. La coronación de sus cuatro torres ilustra dicha referencia" (L'Architecture 1938).

Esa identidad nacional a través del estilo fue cuestionada expresamente por Le Corbusier en el Pabellón Suizo, apostando decididamente por la modernidad. El "no recordar nada a un chalet suizo" -en expresión coetánea suya - fue ocasión de duras reacciones en la prensa helvética. Le Corbusier diria: "Era preciso que Suiza se presentase en París de modo distinto al rostro agreste del poeta". Emblema de los ideales urbanos desarrollados en estas fechas, el edificio contiene gran número de innovaciones tanto a nivel técnico como estético (Zaknic 2004).

En el proceso de proyecto del Colegio y del Pabellón los problemas del estilo y la imagen estaban ligados a los problema del carácter y de la organización tipológica. 


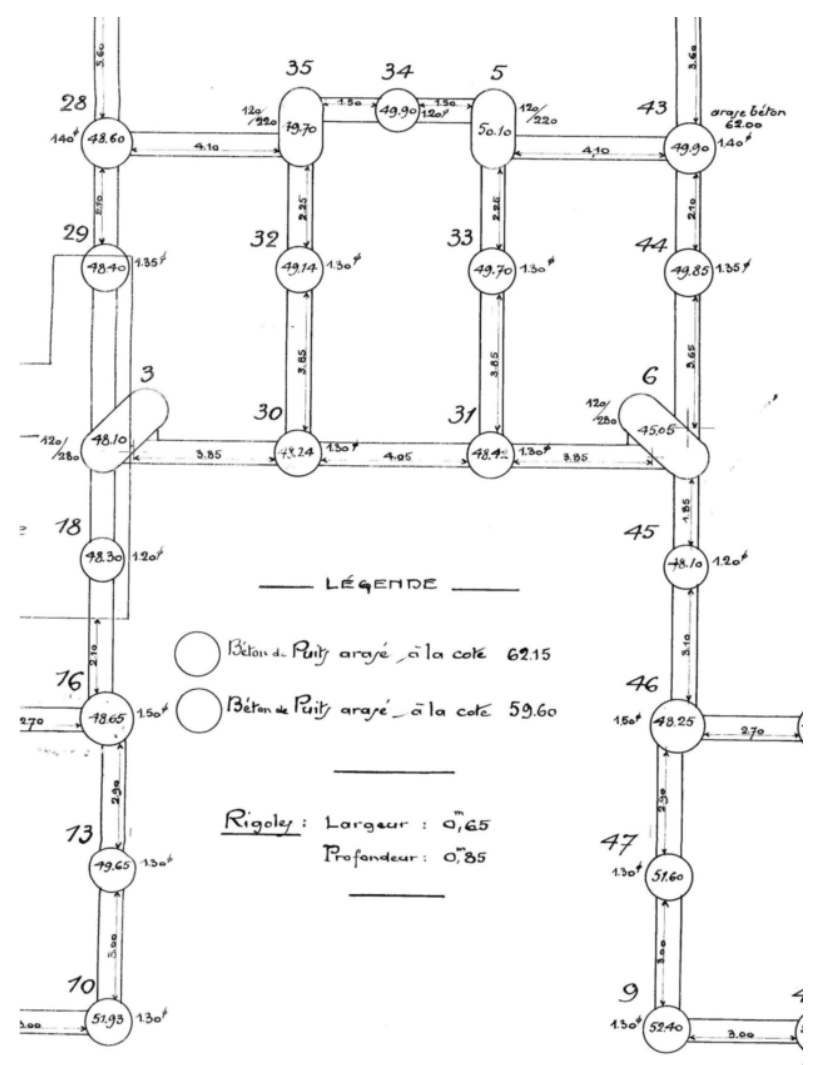

Figura 16. Colegio de España, plano de cimentación, fragmento (archivo ACE).

Figura 17. Pabellón Suizo, sección esquemática de la cimentación(archivo FLC).
Pues la arquitectura de la Cité Universitaire titubeó entre una tradición en que enraizarse y una dificil vanguardia. Junto a la modernidad internacional de Le Corbusier, hubo un experimentalismo de base académica, bien representado por López Otero.

Los problemas compositivos del Colegio de España evidencian esos ideales que indagan sobre las bases mismas de la arquitectura. Se identifica el problema arquitectónico con el del clasicismo y de la composición, buscando un equilibrio entre tradición y renovación que se vería reflejada, más que en el Colegio de España, en los proyectos de su joven equipo de colaboradores en la Ciudad Universitaria.

Por su parte, el proyecto del Pabellón Suizo financieras como una "ocasión de constituir un verdadero laboratorio de arquitectura moderna", como dirá Le Corbusier que, en diciembre de 1931, recién iniciadas las obras, concede una entrevista a un diario suizo, donde da razón de los puntos principales del proyecto, Con el título: "La Maison de Verre", hace de la casa de cristal el emblema del Pabellón. "El máximo de luz: tal es mi formula --dice--. Imaginese una caja de $45 \mathrm{~m}$ de largo, 9 de ancho y 10 de altura. Es el Pabellón Suizo. Uno de los lados mayores de esta caja no es más que un panel de vidrio". Algo así como "un aprovechaba las dificiles circunstancias escaparate de 450 m2", añade. Asimismo, aplicando de manera explícita sus cinco puntos, hace de las dificultades de cimentación una razón proyectual para elevar el edificio sobre robustos pilotis y renunciar a toda planta baja convencional, haciendo de ello base de la composición arquitectónica. "Mis cuatro gruesos pilotis que surgen de la tierra sostendrán el pabellón en alto sobre una pradera" (Zaknic 2004). Una pradera-jardin que hace realidad en el Pabellón Suizo sus ideales de Ville Radieuse.

\section{La arquitectura y los sistemas estructu- rales}

La voluntad arquitectónica se justifica, pues, por razones fisicas: por encontrarse el edificio sobre las canteras subterráneas de la ciudad. El terreno de la zona estaba calificado como "calcaire grossier", cubriendo una zona subterránea irregularmente distribuida al sur de París. "Imposible construir directamente sobre el suelo. Hay que perforarlo e ir a buscar a $12 \mathrm{~m}$ más abajo el suelo de la cantera", dice Le Corbusier. Así pues, entre las circunstancias a las que tuvieron que enfrentarse el Colegio y el Pabellón destaca en primer lugar la relativa a la naturaleza del suelo.

En abril de 1929, López Otero y Boby inspeccionaron el terreno para las obras de cimentación del Colegio de España que, afirmaron, "se presenta dificil". Antes de acometerla, se realizaron sondeos y pros-

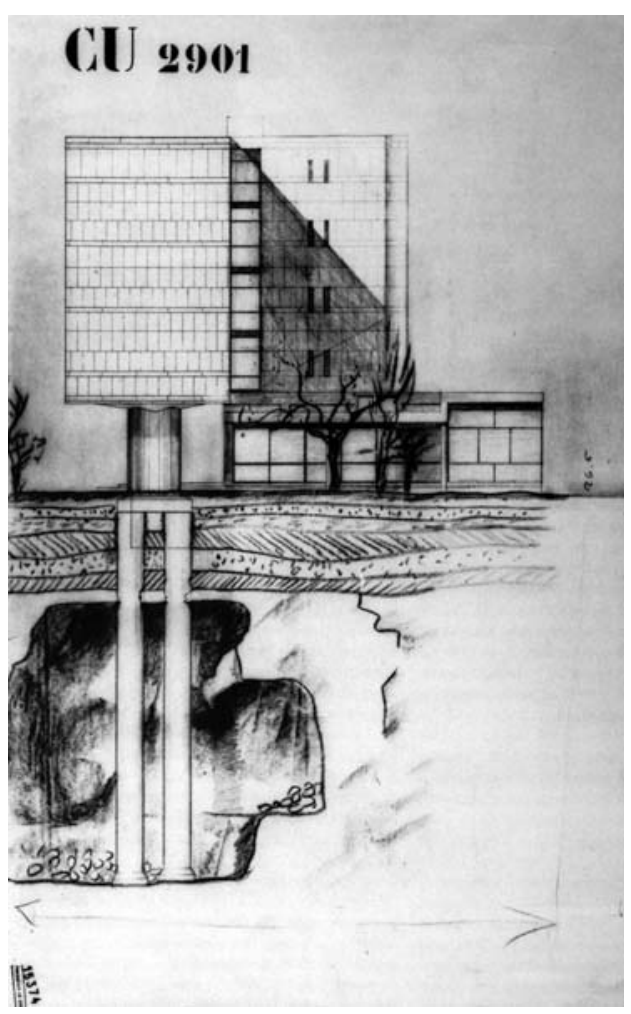


Figura 18. Pabellón Suizo, sistemas estructurales: pilotis y porche (archivo AFS)

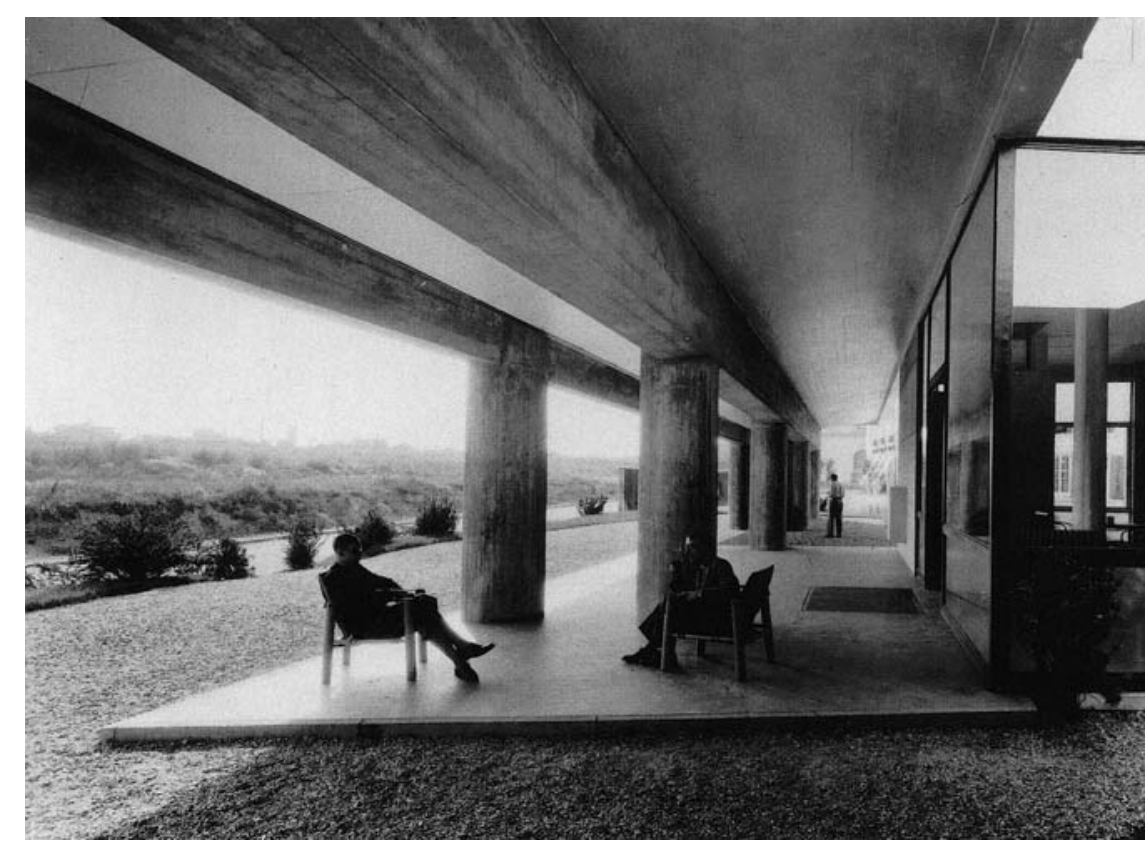

pecciones a cargo de la prestigiosa empresa Roche \& Plaudet, especializada en cimentaciones de hormigón. Plaudet era un ingeniero experto en mecánica del suelo, movimiento de tierras, cimentaciones, sondeos y consolidaciones subterráneas; Roche era un empresario de amplia experiencia constructiva. El archivo del Colegio conserva 6 gruesas carpetas con los resultados y la memoria de los trabajos ejecutados (1929-1930), con planos de cotas y base de cimentaciones, enfocadas finalmente de modo convencional a base de pozos, zapatas y muros de atado (figura 16). Muros de sótano "gigantescos, mucho más caros", que censuraria Le Corbusier al ser cuestionado por su sistema.

Pues en el Pabellón Suizo abordaría Le Corbusier de modo completamente distinto la cimentación, y haria de ella uno de los emblemas de su respuesta arquitectónica y estética. Conocía las dificultades del terreno y sabía de los problemas a afrontar. Lo que quizás no sabía era la magnitud concreta del problema y ello explica el cambio de material de los pilotes: primero metálicos, luego de hormigón armado, según el ajuste estructural propuesto por el ingeniero Hans Weber, y el que las perforaciones y pilotajes del cuerpo principal desciendan a $19.50 \mathrm{~m}$ bajo el suelo tras atravesar la base de canteras (figura 17). La solución adoptada de seis pilotes o pilarotes produce una economía considerable sobre los otros procedimientos. Estética y resistente a la vez, la forma de los pilotis suponía una economía estructural. Ello trajo como consecuencia arquitectónica el uso abierto del nivel de acceso, creando un porche exterior, abierto a los campos de deportes y al jardín de la Cité Universitaire (figura 18). Es decir, la respuesta a un problema estructural real, permitía a Le Corbusier llevar a la práctica uno de sus más conocidos y discutidos puntos-base arquitectónicos.

Aparte de la cimentación y su trascendencia en el proyecto arquitectónico del Pabellón, en su construcción tanto éste como el Colegio recurrieron al hormigón, si bien de modo muy diverso y reflejo de condiciones $\mathrm{y}$ valoraciones diferenciadas.

En las primeras décadas del siglo XX, el hormigón llegó a simbolizar la modernidad arquitectónica o, al menos, constructiva. Si durante años se consideró como un atrevimiento, poco a poco razones utilitarias y de seguridad contra incendios llevaron a emplearlo cada vez más, ${ }^{4}$ comenzando hacia 1917 un extraordinario desarrollo del hormigón armado, con una floración de procedimientos y métodos de cálculo, de los que la patente Dom-Ino corbuseriana es una muestra significativa.

En el Colegio el sistema constructivo utilizado consistió en muros exteriores portantes y forjados de hormigón armado. En contraste con la propuesta Dom-Ino y con los sistemas españoles, que eran y son preferentemente estructuras de esqueleto, con un entramado ortogonal de pilares y vigas, las estructuras francesas de hormigón tendian a ser, entonces y ahora, estructuras preferentemente murarias: muros de hormigón, sobre los que apoyaban planchas más o menos aligeradas de ese mismo material. El contraste entre uno y otro sistema, obligó a alterar el proceso de cálculo previsto al trasladar el proyecto 


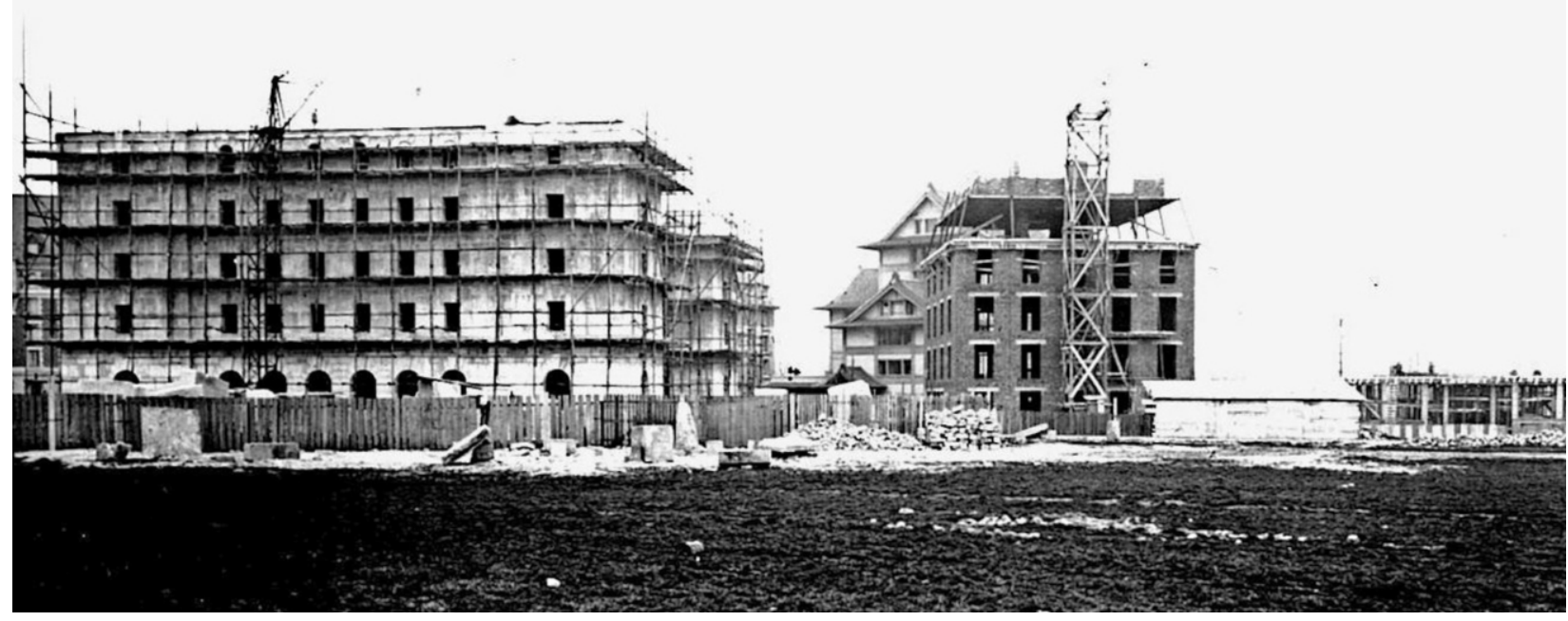

Figura 19. Colegio, foto de obra, mostrando sistema constructivo (archivo ACE).

Figura 20. Colegio, foto de obra, mostrando sistema constructivo (archivo $A C E$ ).

Figura 21. Pabellón Suizo, sistemas estructurales: esqueleto metálico (archivo AFS). del Colegio a los medios parisienses, y supuso pasar de los técnicos habituales como Valentín Vallhonrat ${ }^{5}$ al joven ingeniero Eduardo Torroja (1899-1961), recién incorporado al equipo de la Ciudad Universitaria, quien se desplazó a París para analizar los sistemas constructivos franceses y reflejarlos en el proyecto (ACE 148.2.23). Las relaciones entre Torroja y Warin y la profesionalidad de éste como director conseguirian el resultado deseado (figuras 19, 20).

Por su parte, en el Pabellón renunció Le Corbusier a sus bases Dom-Ino y planteó una estructura mixta, que utilizaba el hormigón solamente en las subestructuras y en los pilotis, montando luego sobre ellos un esqueleto o jaula ligera metálica de acero. ${ }^{6}$ Frente a la idea de una osatura estándar, resultó así un conjunto mixto formado por una plataforma de hormigón amado de 42,50 m de longitud, soportada en su eje longitudinal por una viga doble de canto apoyada en una hilera de seis robustos pilotis de hormigón, sobre la que se alzaba la estructura superior, calculada y ejecutada por Bosson \& Lepeu, una conocida empresa parisiense de construcciones metálicas, que publicitaría luego el Pabellón en su propaganda, dando fe de la importancia concedida al resultado arquitectónico (figura 21). Resulta asi una estructura mixta de caja ligera y homogénea sobre una bandeja de vigorosas patas. "Sorprende ver a una estructura resistente servir tan dócilmente una idea arquitectónica" (Curtis 1981)

\section{Elementos y procesos constructivos}

La construcción del Pabellón --escribió Le Corbusier (Oeuvre 1934) - fue la ocasión de constituir un verdadero laboratorio de arquitectura moderna". Si la estructura fue una ocasión para plantear nuevos sistemas arquitectónicos, en las fases siguientes se abordaron igualmente problemas novedosos, en particular los de la construcción en seco y la insonorización, y
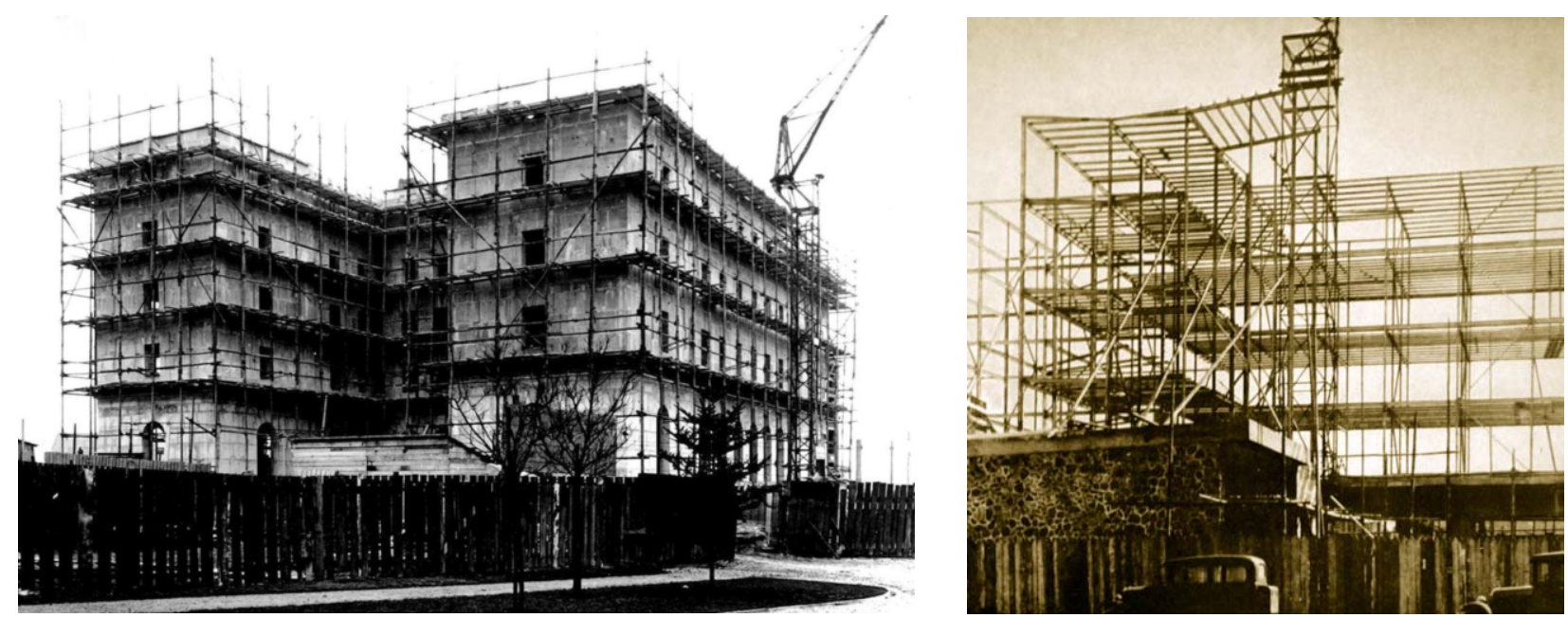

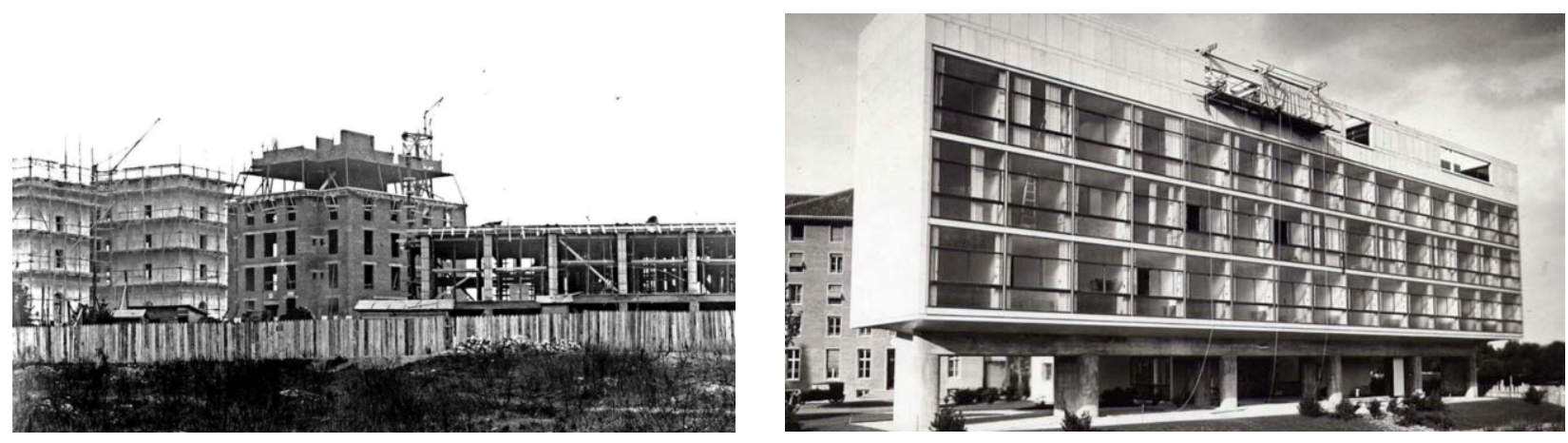

Figura 22. Colegio y Pabellón, procesos constructivos, fotos de obra (archivo ACE).

Figura 23. Pabellón Suizo, sistemas constructivos: el pan de verre (archivo AFS).

Figura 24. Pabellón Suizo: elementos constructivos de la célula (Oeuvre, 1934). el del pan de verre o muro acristalado (figuras 22, 23, 24).

Le Corbusier recurrió para todo ello a su empresa habitual: R. Glauser \& G. Summer, ingenieros-constructores, que ya habian trabajado con él en las villas Jeanneret y La Roche, en la villa Stein, en la maison Plainex, en el Pabellón de L'Esprit Nouveau, y en el edificio de viviendas de Porte Molitor. Glauser y Summer se hicieron cargo tanto del proceso de desarrollo del proyecto básico corbuseriano llevándolo a proyecto de ejecución en el verano de 1931, como, luego, de la construcción y ejecución de obras hasta su finalización (AFS).

Sobre el entramado estructural metálico se aplicaron sistemas novedosos con procedimientos y patentes especiales para construcción en seco e insonorización, mezcla de fibras de asbesto y cemento, como Insulithe o Lignat para los techos, o Everite para los tabiques entre habitaciones, este último material muy vinculado a Le Corbusier, que había dirigido la 'Société des Applications de l'Everite' en 1918. Ambos

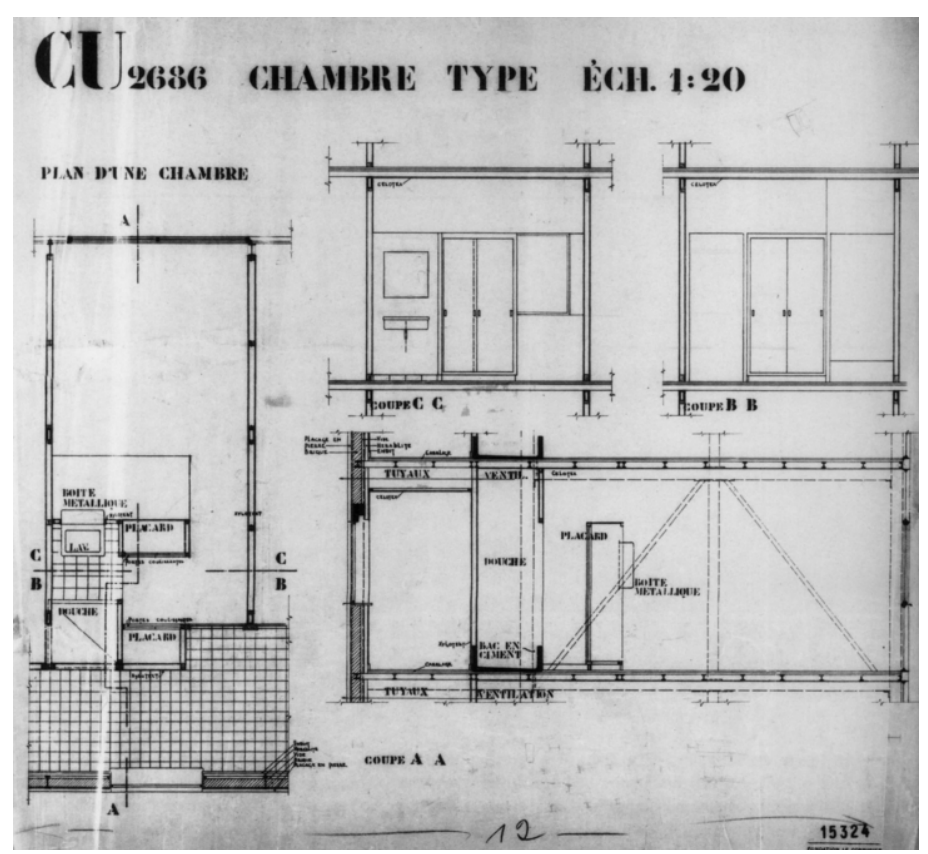

garantizaban rapidez, economía y aislamiento fónico en paredes, techos y suelos, siempre con una puesta de obra en seco (Alonso 2015).

Le Corbusier propugnaba una estética moderna por medio del empleo de materiales nuevos. Frente a los 'materiales nobles' utilizados como revestimiento obligado en los restantes edificios de la Cité: piedra de talla o ladrillo visto, Le Corbusier defendió e introdujo en el Pabellón los que llamaba 'materiales sanos': hormigón sin tratar en los pilotes, muro de mampostería en el pabellón comunitario, revestimiento en placas de cemento vibrado en la fachada norte, pared de pavés en la escalera, o un pan de verre acristalado en la sur, haciendo de todos ellos el emblema de la nueva arquitectura.

Por su parte, el Colegio contrató en marzo de 1930 la obra general con la Maison Lemoüé, firma prestigiosa en el mundo parisiense de la construcción, premiada en diversos concursos municipales (ACE 148.6.113). Como se ha indicado, los muros y forjados fueron de hormigón armado, con tabiques interiores de ladrillo. Pero, aunque los muros fueran de hormigón, en ningún momento se planteó dejar éste visto (ACE 149.1.189), sino que siempre se pensó en su revestimiento como elemento a la vez constructivo y expresivo del Colegio, reforzando la claridad arquitectónica del proyecto. ${ }^{7}$ Los muros exteriores se revistieron en caliza semidura Tercé Normandoux, fijada con mortero, al igual que el ático y las cornisas de coronación, en tanto que los motivos y esculturas rematando los pabellones se realizaron en piedra de Laveux.

La cubierta fue de zinc a dos aguas, sobre cerchas de madera ejecutadas por Bourgignon \& Bertet. Los pavimentos fueron de dos tipos: en piedra o mosaico y en linóleum o parquet sin juntas Porphyrolithe. De los primeros se encargó Christofoli \& Martinuz; de los segundos se hizo cargo Agglomérés Magnésiens Magnolithe, según una patente muy empleada por esas 


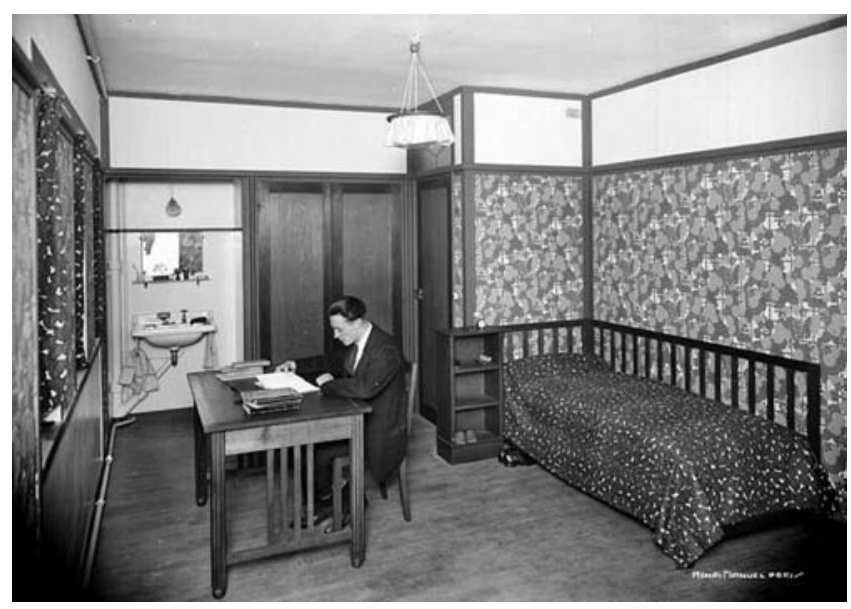

Figura 25. Célula de habitación de la Fundación Deutsch (archivo CUP).

Figura 26. Célula de habitación del Pabellón Suizo (archivo AFS). fechas en diversas obras francesas, como el Ayuntamiento de Boulogne-Billancourt de Tony Garnier. De la pintura y vidriería se encargó Diolé \& Decloux, en tanto que Formerot \& Grégoire, ejecutaron los remates escultóricos y los pináculos.

Parte importante de las obras fueron las distintas instalaciones. Si en el Pabellón se encomendaron siempre a distintas empresas suizas, como Schlinder: el ascensor, y Sulzer, la calefacción central, en el Colegio corrieron a cargo de empresas francesas. Pommier \& Delaporte, establecimientos conocidos ya desde la Exposición de 1900, ejecutaron la calefacción; la ventilación y agua caliente, la empresa G. Anceau; la

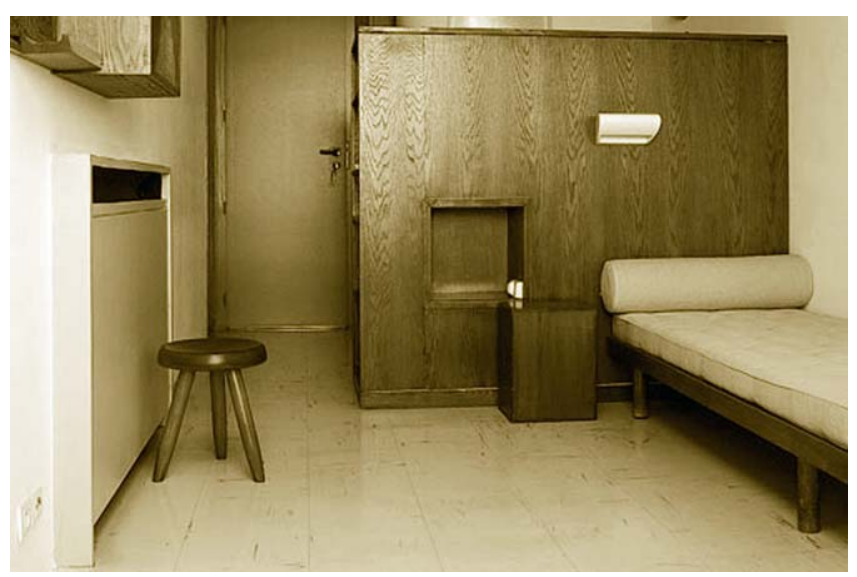

electricidad, Alloncle \& Larose y la Cie. Parisienne de Distribution d'Électricité, en tanto que la instalación del ascensor se encargó a la célebre Maison Roux-Combaluzier, que había sido una de las fabricantes de los elevadores de la Torre Eiffel.

\section{Las células de habitación}

Parafraseando la célebre expresión corbuseriana, el Pabellón Suizo, el Colegio de España y, en general, toda la Cité Universitaire de París es una 'machine à habiter en collectivité': un intento de combinación de la vida privada y la vida comunitaria. $\mathrm{La}$ conciliación entre ambos valores se abordaría mediante el concepto y el proyecto de las células de habitación (figuras 25, 26, 27, 28, 29).

Para le Corbusier, los principios urbanos se definen a través de la célula de habitación, con unas características abstractas que hacen posible el proyecto como una suma de elementos funcionales articulados por elementos singulares aglutinadores. Así, la voluntad de relacionar ciudad y célula: unidad máxima y unidad mínima de agregación le llevó a diferentes propuestas que, aunque culminaron tras la Guerra Mundial en la Unité d'Habitation, tienen su base en proyectos anteriores como la Cité Refuge (1929) y el Pabellón Suizo (1930), cuyas características le permitieron aplicar la metodología moderna de composición arquitectónica y abordar el proyecto como una suma de elementos repetibles articulados por elementos singulares aglutinadores, que se trataban enfatizando su singularidad.

Por el contrario, el Colegio de España renunciaría a individualizar el módulo repetible, considerándose secundaria la célula-habitación en el proceso proyectual y sacrificando su forma-tipo a la del conjunto: a su composición y a su imagen exterior.

La Fundación Deutsch había fijado los datos esenciales del programa, como la
Figura 27. Célula de habitación del Colegio de España larchivo ACE).

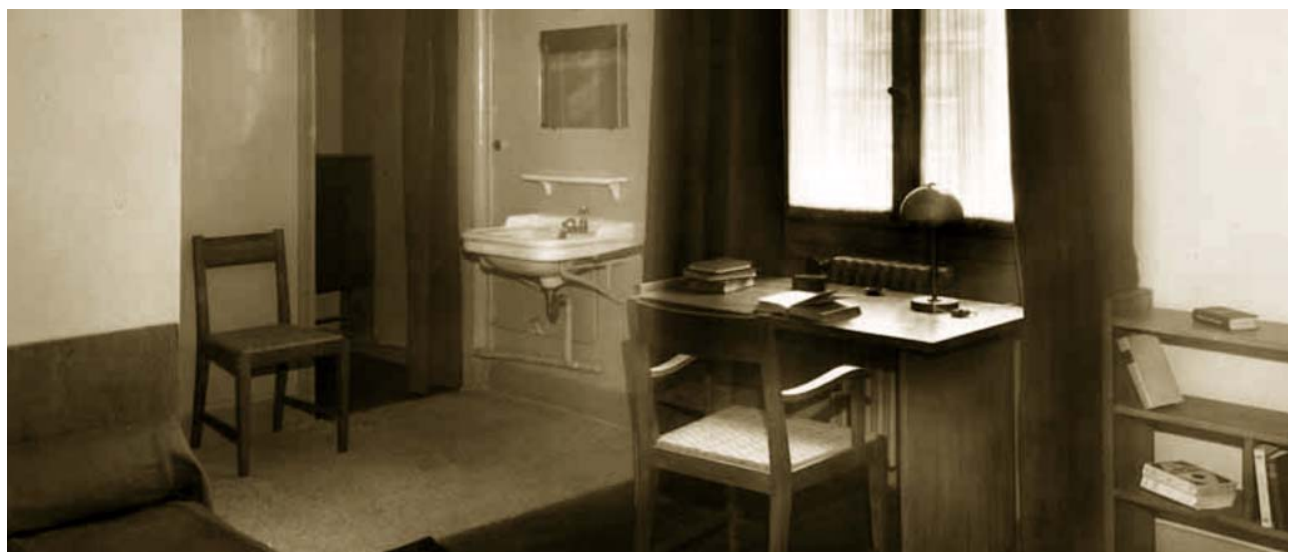


Figura 28. Pabellón Suizo, adecuación y mobiliario de la sala común (archivo FLC).

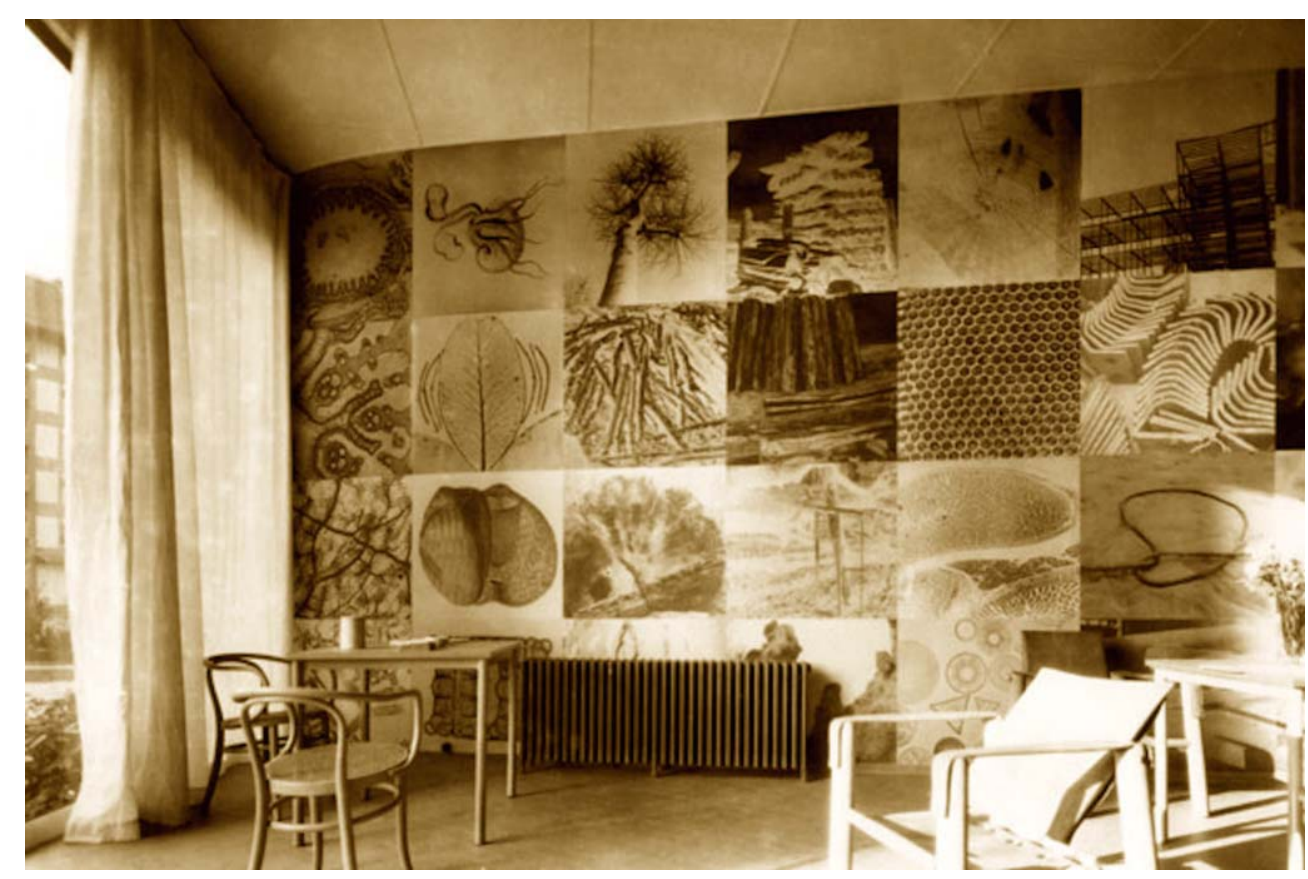

dimensión media de las habitaciones o la cualificación de los espacios de vida común. En la Deutsch --base y fundamento de todas las demás fundaciones de la Cité--, las células eran de 4,20 x 3,50, o sea, 14,70 m2. Cada una estaba amueblada y equipada con un canapé-lit o camasofá, una mesa de trabajo, un armario ropero y un área-lavabo o cabinet de toilette, siendo colectivos las duchas y baños (Dreyfus-See 2000).

Aunque cada nueva residencia tendió a mejorar la calidad y las superficies, integrando los datos sociales propios, las bases de la Deutsch se manifestaron claramente aún en el Colegio de España donde López Otero definía el cabinet de toilette y el ropero como anejos al dormitorio, formando conjunto con él.

Estas bases fueron, sin embargo, abiertamente cuestionadas por Le Corbusier en el Pabellón Suizo. Acudió para ello tanto a su reflexión proyectual como a su memoria personal. La célula del Pabellón quiso situarse en el centro del jardín, haciendo que sus ocupantes formasen parte a la vez de la ciudad y del campo o sea, estuviesen en una Ville Radieuse. Por otro lado, apostó decididamente por la higiene como elemento de progreso e hizo emblema de ella sus células de estudiante, incorporando la ducha individual a ellas, caso insólito en el hábitat y en la hostelería de su tiempo.

El problema de la célula se liga al equipamiento interior: al mobiliario. La mecanización había llegado del mobiliario al habitáculo. Recorriendo el camino inverso, Le Corbusier fue pasando poco a poco en sus propuestas de la presencia de muebles comunes indiferenciados a la inclusión de muebles industrializados o especializados, como reflejarian sus dibujos de interiores en estos años y en los sucesivos (Alonso 2015).

Le Corbusier entendió, pues, la adecuación interior del Pabellón como un verdadero problema de arquitectura. Por un lado, concibió los elementos fijos como arquitecturas-mueble, cuya función era articular los espacios. Por otro, quiso hacer de los muebles una arquitectura de pequeña escala, bien proyectándolos o bien escogiéndolos con cuidado en casas de fama internacional, como Maple: los sillones Franklin y Newstead, Thonet: las sillas en madera curvada, Ronéo: las puertas metálicas, Chalier: los reflectores y lámparas, valorando los productos industriales tanto por su racionalidad como por su estética, y complementándolos con muebles de diseño propio, realizados junto con Charlotte Perriand (Barsac 2015).

Asimismo, el amueblamiento del Colegio de España mostraría influencias europeas, que bascularian entre las formas clasicistas y las formas modernas ya estandarizadas en la arquitectura escolar del momento (Jiménez 1964). Tanto López Otero como Alberto Jiménez Fraud (1883-1964) —creador y director de la Residencia de Estudiantes de Madrid, y responsable de la finalización del Colegio de España durante la República - conocian y hacian referencia en sus escritos a las publicaciones de Paul Griesser y Adolf Schneck, fundamentales para entender el diseño alemán de esos años. El primero editaba 'Das Neue 
Figura 29. Mobiliario Fundación del Amo en la Ciudad Universitaria de Madrid (archivo $A C E)$.

Figura 30. La Cité Universitaire en 1936: grupo de residentes en el Colegio de España (archivo ACE).

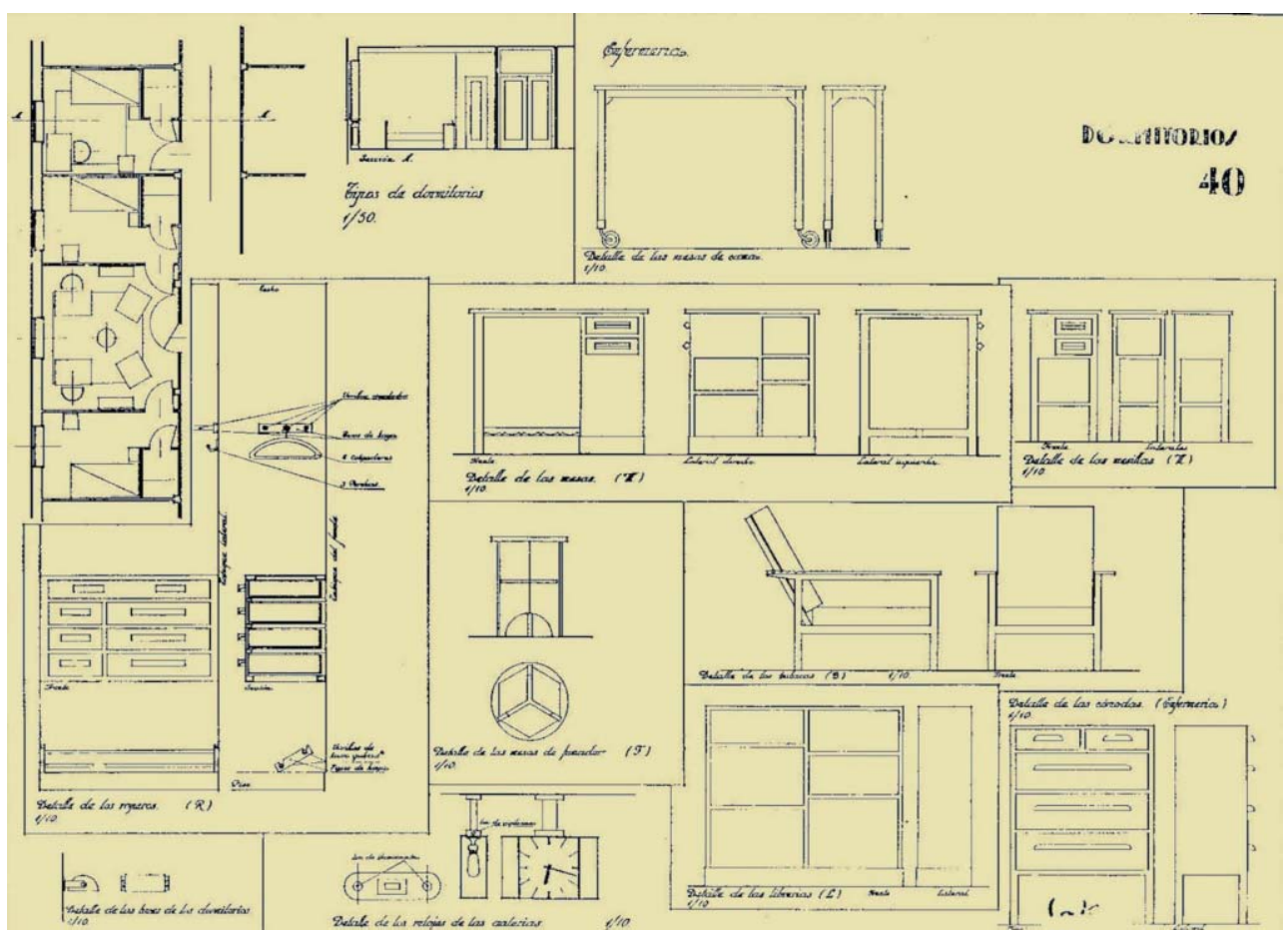

Mobel', revista tipo Bauhaus, vinculada al Deutscher Werkbund. El segundo era un conocido diseñador de mobiliario y un representante de la nueva arquitectura alemana. En todo caso, López Otero aconsejó controlar los diseños, tanto si los muebles se importaban de España como si se fabricaban en Paris, y dibujó esquemas de carpinterías, muebles, lámparas y otros motivos (ACE 149.1.1), al modo que por las mismas fechas hacian Bergamin y Blanco Soler en la Ciudad Universitaria de Madrid (figura 29).

\section{Conclusión}

A través de la secuencia ordenada entre el hecho urbano, arquitectónico, compositivo y constructivo hemos analizado y constatado cómo el Pabellón Suizo y el Colegio de
España representan bien el tiempo entre la primera y la segunda Guerra Mundial en la arquitectura. Ambos reflejan el amplio registro cultural de la Cité Universitaire de París y la pluralidad de la arquitectura de su tiempo. Si el Pabellón Suizo es un emblema del Movimiento Moderno, el Colegio de España simboliza los compromisos académicos aún vigentes. El análisis comparativo de sus arquitecturas ha mostrado múltiples facetas de la relación dual entre ambos en sus procesos proyectivos y constructivos. Vecinos y coetáneos, el enfrentamiento dialéctico entre ambos nos ha revelado aspectos poco conocidos de sus respectivas arquitecturas, al tiempo que la coincidencia del tema y el paralelismo del lugar nos han permitido analizar un tiempo histórico que se debate en toda Europa entre tradición y vanguardia (figura 30).

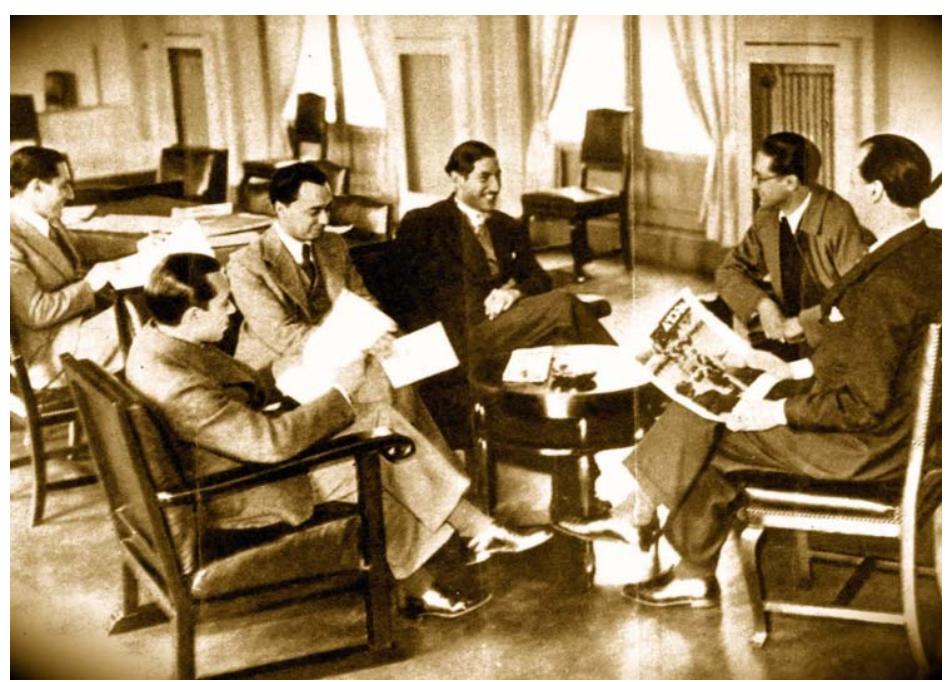

Notas

1. Desde 1924 el Gobierno tenía intención fundar una institución cultural española en París, similar a la Casa de Velázquez francesa, entonces en construcción en Madrid. El propósito se encarriló en junio de 1927, cuando Alfonso XIII, en una visita a París, escogió el emplazamiento: un terreno junto a los colegios franco-británico y belga, japonés y estadounidense, que planteaban edificios de 200 o 250 habitaciones; y pensando que las atribuidas a España no estaban a la altura del prestigio nacional, se elevaron a 150 , reservando algunas para estudiantes hispanoamericanos.

2. En octubre de 1927 se creó el Patronato para el Colegio, encabezado por el duque de Alba como presidente de la Junta de Relaciones Culturales. En abril de 1928, se nombró a Luis Doreste "encargado de los asuntos relacionados con la construcción del pabellón”. 
Seguidamente, se encargó a López Otero el proyecto.

3 Redactado en Madrid de acuerdo con los procesos y sistemas españoles, para su ejecución material el proyecto fue desarrollado en los medios franceses. En julio de 1928 se contrató para dirigir los trabajos a Eugène Boby, que ya trabajaba para la embajada española.

4 Ello unido a la notable variación sufrida en los precios de los materiales a causa de la Guerra Europea -que, afectándoles de forma desigual, benefició mucho al hormigón armado- hizo que a partir de 1917 comenzara en España un extraordinario desarrollo del nuevo sistema constructivo.

5 El ingeniero Valentín Vallhonrat Gómez (1884-1965) creó y dirigió una de las más destacadas empresas especializadas del momento; desde 1918 colaboró como constructor y como calculista en obras significativas como el Hotel Savoy de Madrid, el Banco Pastor de Coruña, el Hotel Carlton de Bilbao, y otras de López Otero como La Unión y el Fénix de Madrid o el Gran Hotel de Salamanca, coetáneas del Colegio.

6 A esta decisión ayudó el corto presupuesto asignado para la construcción: tres millones de francos, cantidad que Honnorat consideraba la mitad de la necesaria para llevar a cabo la obra.

7 Se dudó en un primer momento entre el ladrillo combinado con piedra - al modo hispano que se planteaba entonces en la Universitaria madrileña- o la piedra sola, más propia de la arquitectura urbana parisiense, pero siendo del mismo coste en Francia ambos materiales, "resolviose, dado el carácter del edificio y la voluntad preponderante de la Cité Universitaire, emplear piedra" (Doreste 1931).

\section{Bibliografia}

AA. VV. 1933. Le Pavillon Suisse à la Cité Universitaire de Paris. Chantiers, Paris, $\mathrm{n}^{\circ} 1$, ene-feb 1933: 3-19, texto de E. Menkés.

AA. VV. 1933. Le Pavillon suisse à la Cité universitaire de Paris par Le Corbusier et Jeanneret, architectes. La Construction Moderne, París, $\mathrm{n}^{\circ} 14$, dic 1933: 218-229, texto de J. Margerand.

AA. VV. 1938. Pavillon Espagnol à la Cité Universitaire. L'Architecture, París, nº11: 391-396.

Agrasar Quiroga, Fernando. 1990. La humanizada máquina de habitar. Boletín Académico, La Coruña, $n^{\circ} 13:$ 5-10.

Alonso Pereira, J. Ramón. 2013. El Colegio de España en París, punto de intersección entre las ciudades universitarias de Madrid y París. Liño, ${ }^{\circ} 19$ : 65-80. Oviedo.

Alonso Pereira, J. Ramón. 2015. El París de Le Corbusier, Barcelona: Reverté.

BARSAC, JACQUES. 2015. Charlotte Perriand: l'oeuvre complète, vol 1, 1903-1940. Paris: Editions Norma.

Bohigas, Oriol. 1970. Arquitectura española de la Segunda República. Barcelona: Tusquets. Reed. como Modernidad en la arquitectura de la España republicana. (1998) Barcelona: Tusquets.

Caillot, Céline. Colas, Ludovic. 1994. Le pavillon Suisse, Cité internationale universitaire de Paris. Paris: Fondation Le Corbusier.

CAMPos CALVo-Sotelo, Pablo. 2004. 75 años de la Ciudad Universitaria de Madrid: Memoria viva de un campus trascendental. Madrid: Complutense.

ChíAs NAVARRo, Pilar. 1986. La Ciudad Universitaria de Madrid. Madrid: Complutense.

Cohen, Jean-Louis. Lortie, André: Des fortifs au perif: les seuils de la ville, Arsenal-Picard, París, 1991.
CurTis, William. 1981. Ideas of Structure and the Structure of Ideas: Le Corbusier's Pavillon Suisse 1930-1931. JSAH - Journal of the Society of Architectural Historians, Harvard, $\mathrm{n}^{\circ} 4: 295-310$

Doreste, Luis. 1931. Colegio de España en la Ciudad Universitaria de París, informe general y económico, París: Embajada de España.

Dreyfus-See, Genèvieve. 2000. La carrière de Lucien Bechmann (1880-1968), París:

Institute FrançaIS D'ARCHITECTURE, Archives d'Architecture du XXe siècle.

Flores, Carlos. 1961. Arquitectura española contemporánea. Madrid: Aguilar (reed. en 2 volúmenes, 1989).

JiménEZ FrAUD, Alberto. 1970. La Residencia de Estudiantes. Barcelona: Ariel.

LE CoRBusier. 1925. Urbanisme. Paris: Crès; reed. 1994. París: Flammarion.

Le Corbusier. Jeanneret, Pierre. 1934. Oeuvre Complete, vol II, 1929-1934, Zurich: BoesigerGirsberger, Cfr. Pavillon Suisse, 74-89.

LEMOINE, Bertrand. 1990. La Cité Internationale Universitaire de Paris. París: Hervas.

Niño Rodríguez, Antonio. 2004. Bâtir des chateaux en France ou la naissance du collège d'Espag ne à Paris, rev. Siècles, París, $n^{\circ}$ 20: 63-80.

SAZATORnil, Luis. 1997. Le College d'Espagne à Paris. París: College d'Espagne, breve folleto editado por el Colegio de España.

ZAKNIC, Ivan. 2004. Le Corbusier, Pavillon Suisse, the biography of a building, Basilea: Birkhausser.
Fecha final recepción articulos: 30/04/2017

Fecha aceptación:

29/06/2017

Articulo sometido a revisión por dos revisores independientes por el método doble ciego. 